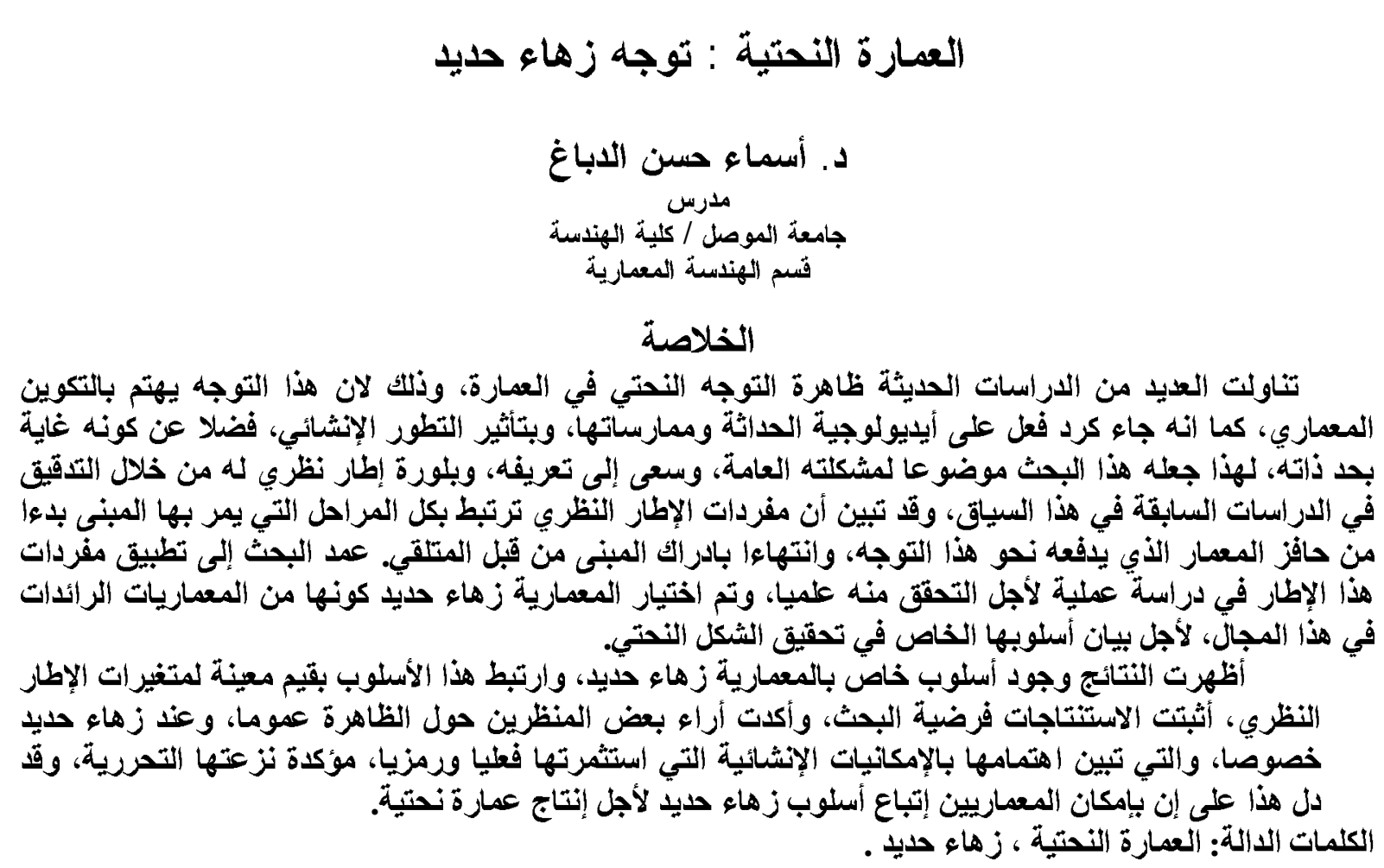

\title{
Sculptural Architecture : The Zaha Hadid's Approach
}

\author{
Dr. Asma Hasan Al-Dabbagh \\ Lecturer / Dept. of Architecture \\ College of Eng. /Univ. of Mosul
}

\begin{abstract}
Previous studies have paid special attention to sculptural architecture because it concerns about architectural composition, this paid attention is also likely to be due to the fact that sculptural architecture has been a reaction to the principles and practices of Modernism, as a result of modern practical developments in the field of construction and as an aim in itself. This paper focuses on the discipline of sculptural architecture seeking its identification and subsequently the establishment of its theoretical framework based on previous research work. The paper shows that aspects of the established theoretical framework can be clearly related to the various phases through which the construction of a given building traverses, ranging from the initial phase of motivation and concept design by the innovating architect to process of building comprehension by recipient. The developed theoretical framework is then verified by addressing Zaha Hadid's pioneering work in this field, which is used here as case study. The application of the theoretical framework has revealed a series of patterns in Hadid's work which may be attributed to her own architectural style. Similar results to those obtained from the theoretical framework have also been made by other observers, all of which point to the special paid attention by Hadid to modern construction methods which she used symbolically and practically confirming her liberal architectural style. The revelations demonstrate the validity of the assumptions made in the development of the theoretical framework. Finally, this paper lays down a set of guidelines for other architects who wish to apply Hadid's approach in sculptural architecture.
\end{abstract}

Keywords: sculptural architecture, Zaha Hadid . 


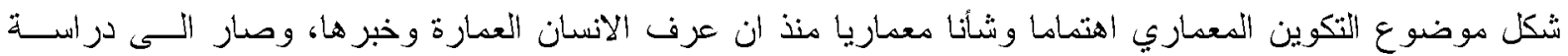

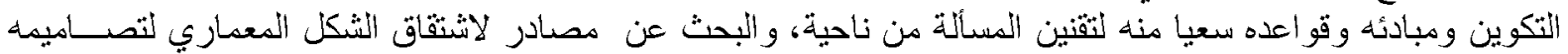

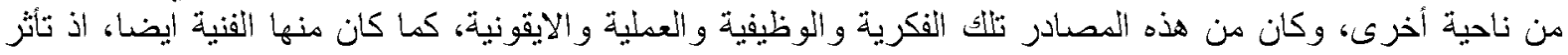

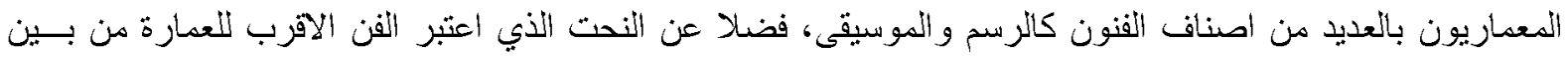

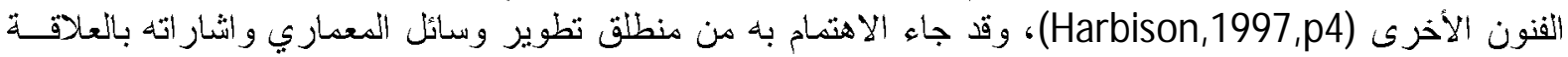

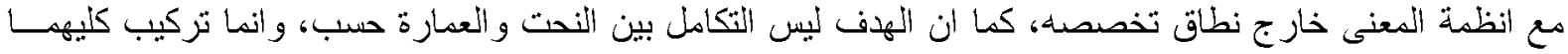
ضمن عمل كامل ذو نسق راق (Sungur,2006).

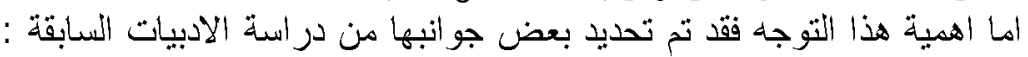

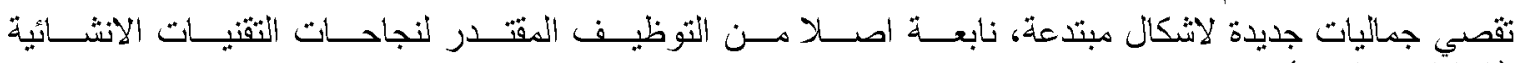
(السلطاني :المدىى)

- المزيد من التقرد ضمن سياق الثكال البيئة المبنية المحيطة ( السلطاني،المدىى)

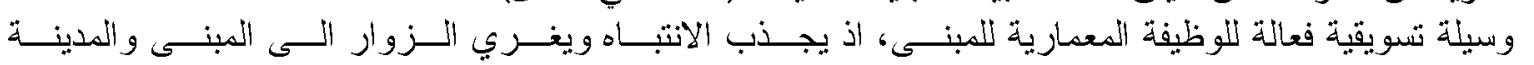
ككل) (Sungur,2006)

نمط من أنماط الاتصال Communication يعبر الفنان من خلالكه عن نفسه عاطفيا وفكريا (Konopka,2003)

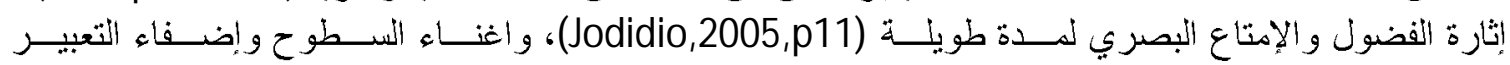

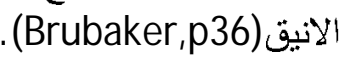

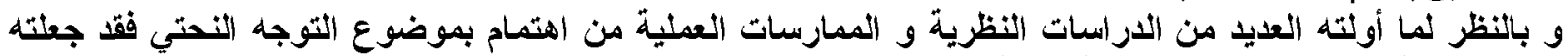

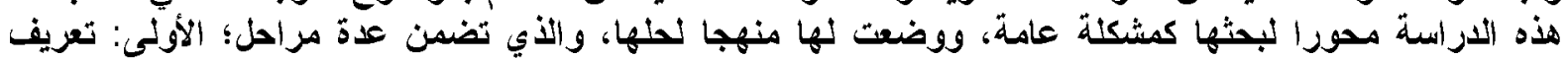

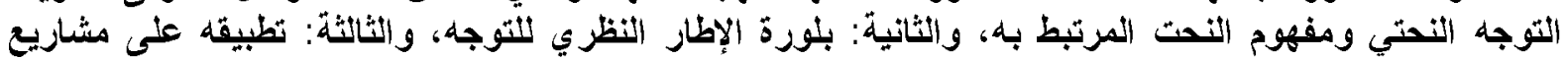

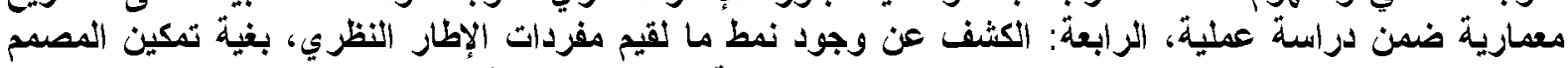

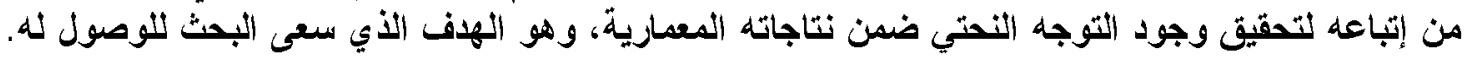

: 2

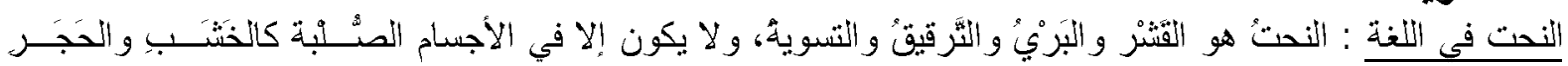

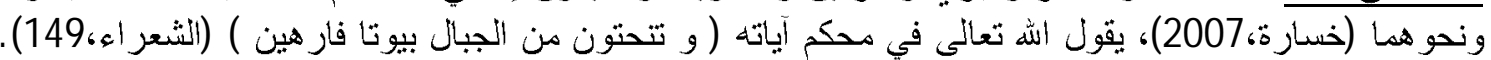

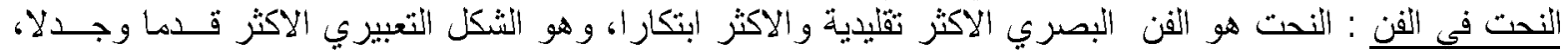

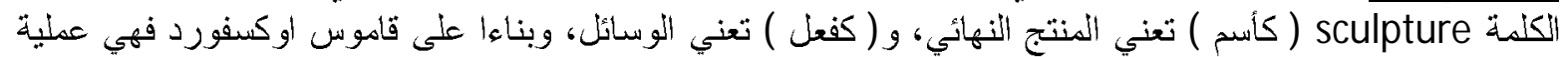

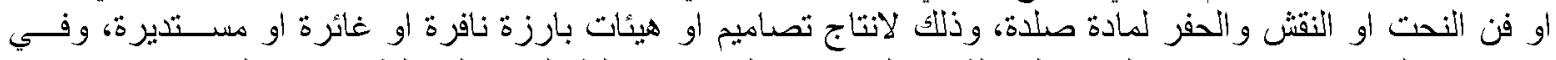

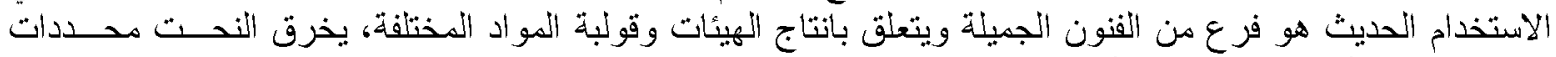

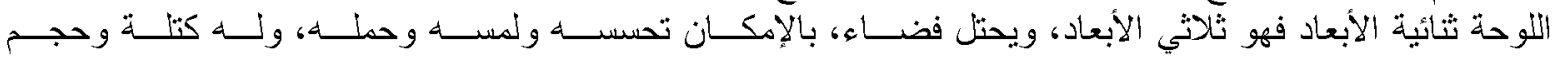

. (Konopka,2003)

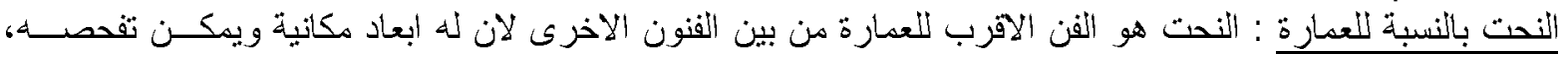

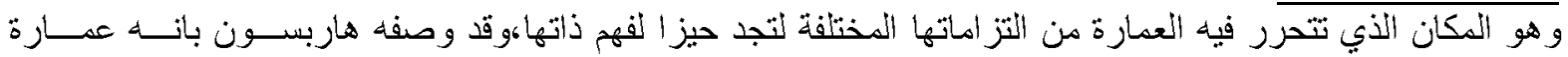

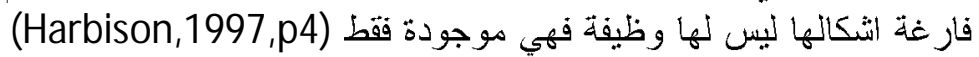

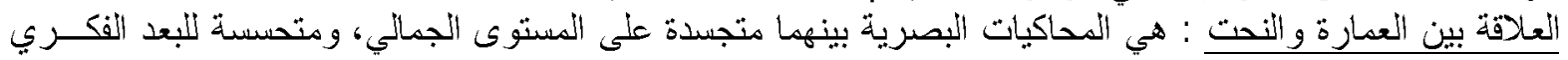

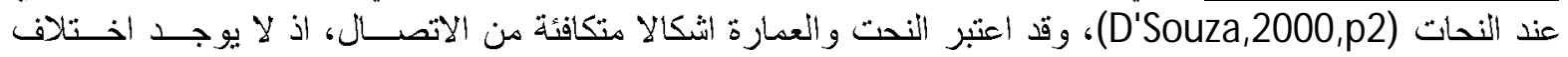

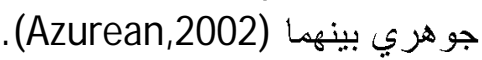

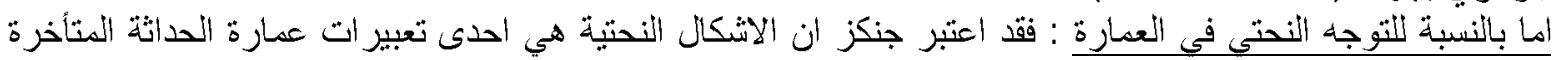

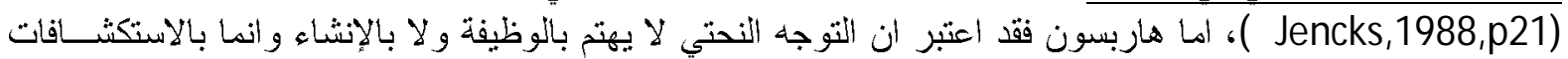

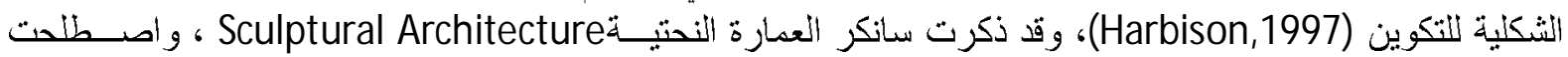

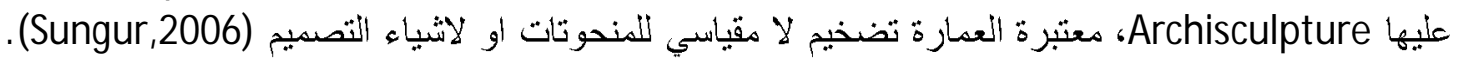

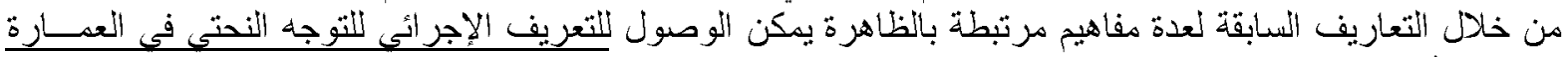

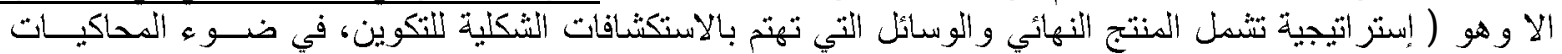

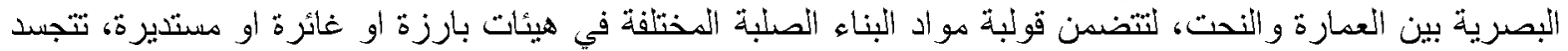

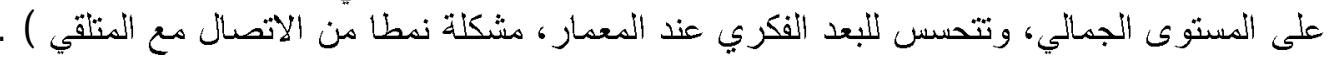




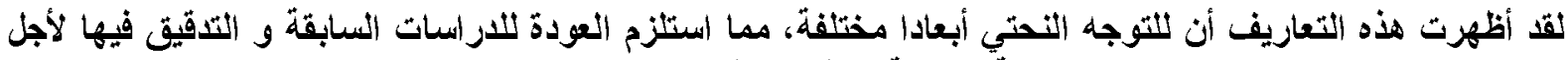

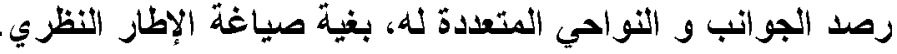

\section{3. الار اسات السـابقة \\ 1.3 دراسات متخصصة في توجه النحتية \\ Robert Harbison " Sculpture " , 1.1 دراسة 1.3}

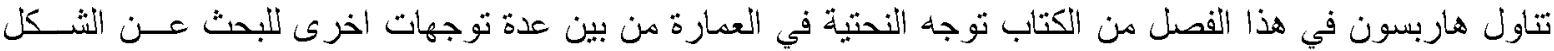

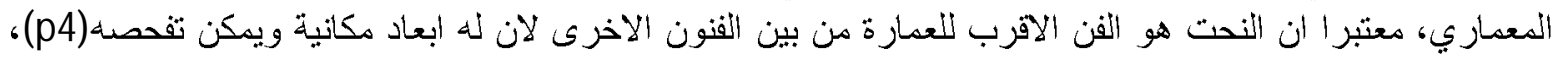

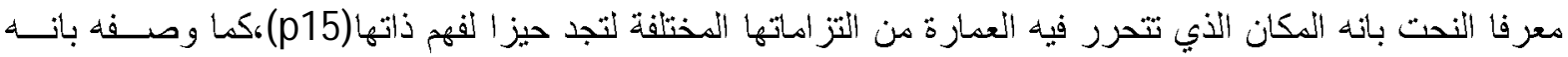

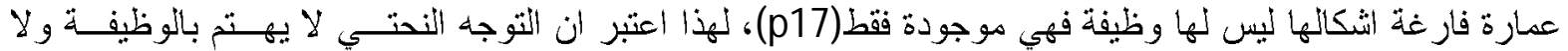

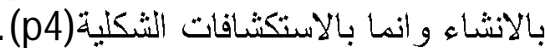

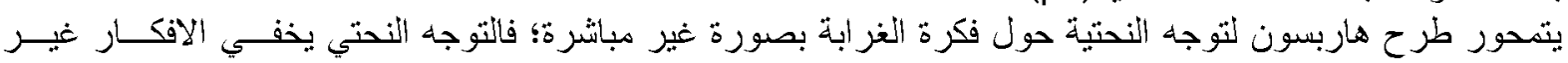

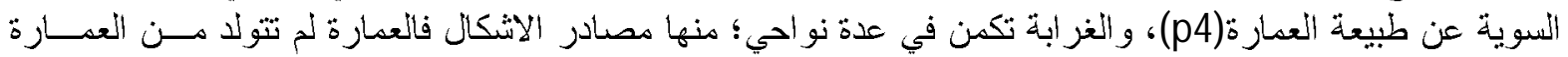

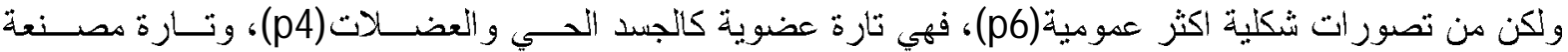

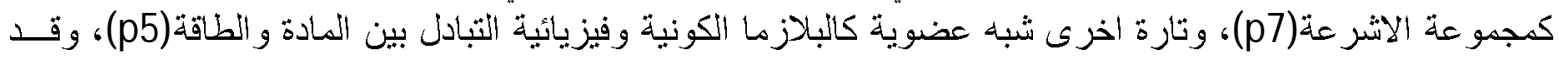

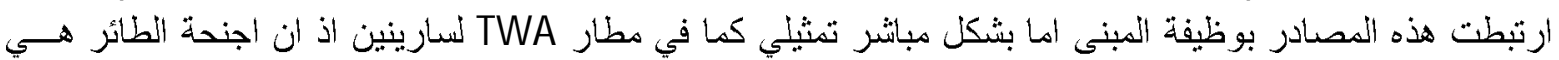

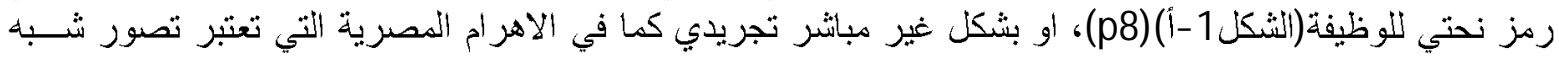

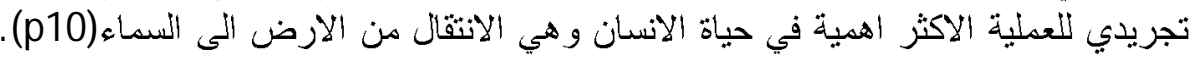

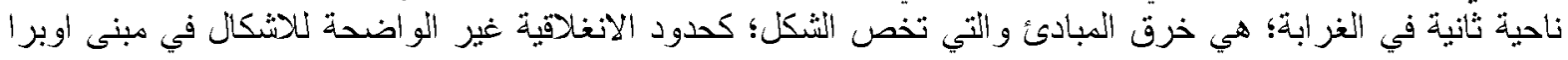

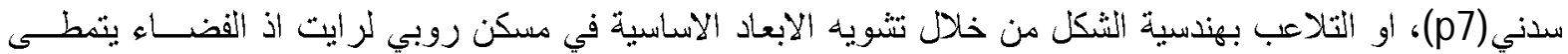

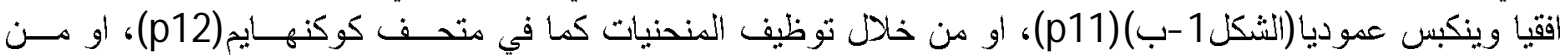

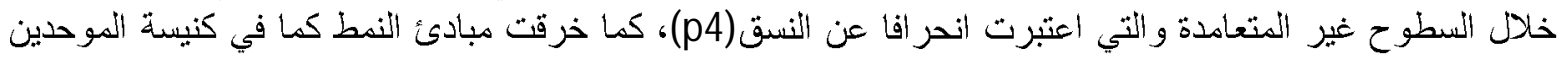

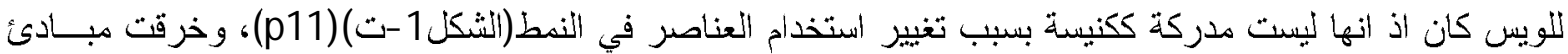

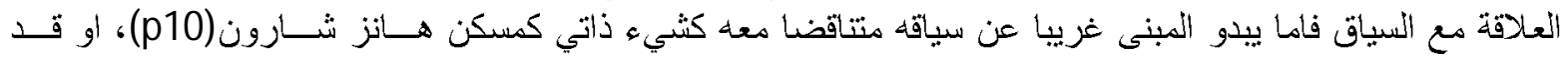

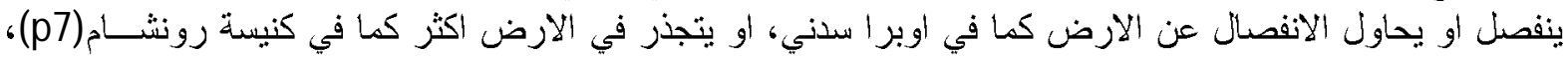

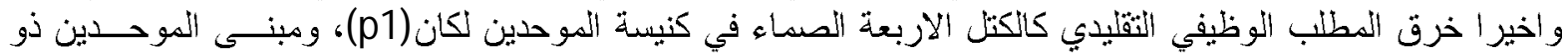

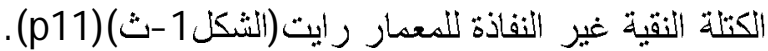

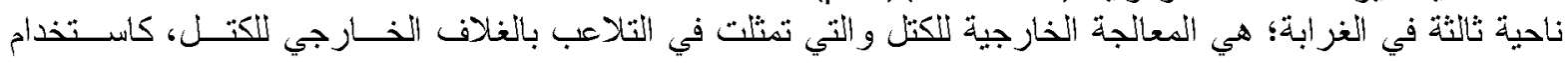

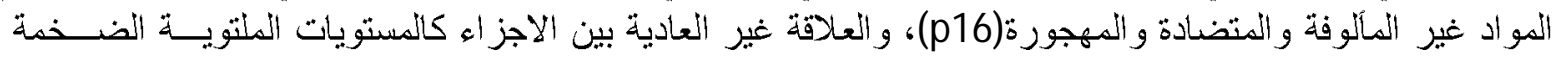

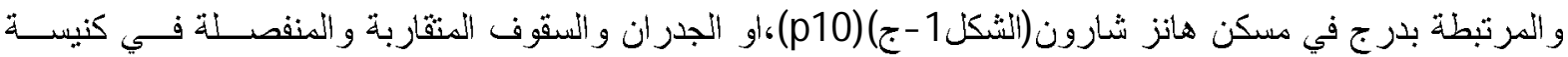

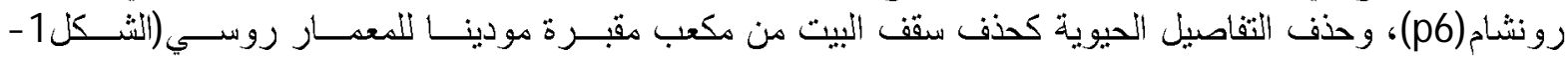

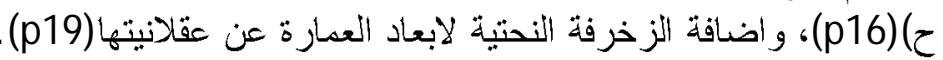

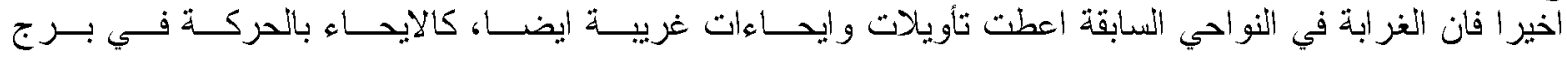

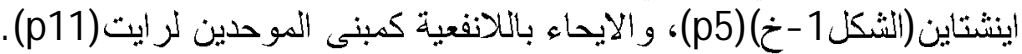

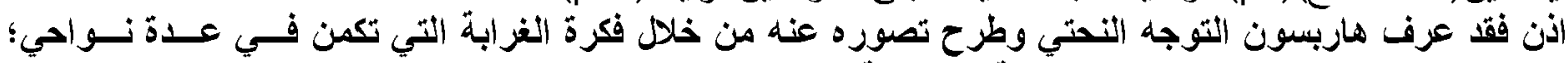

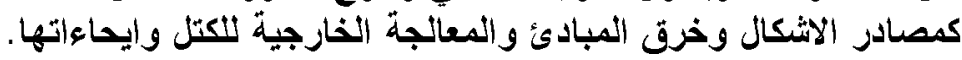

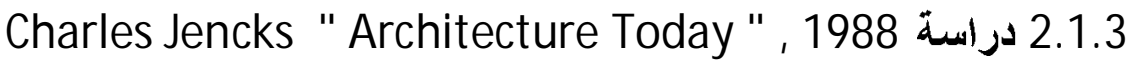

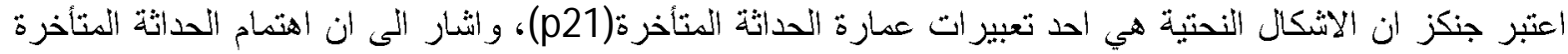

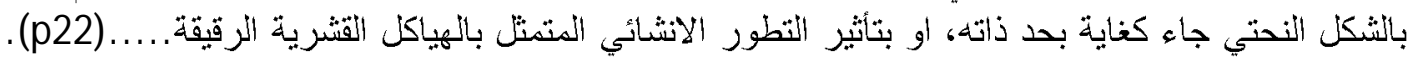

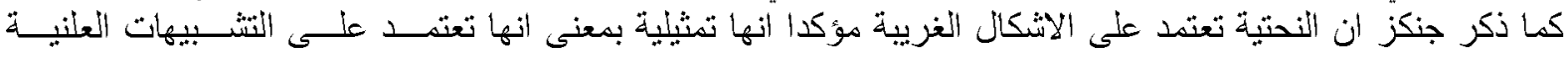

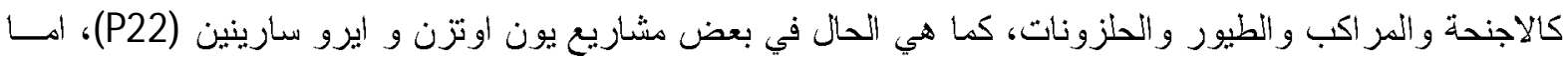

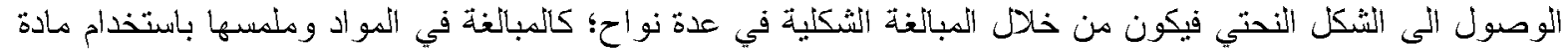

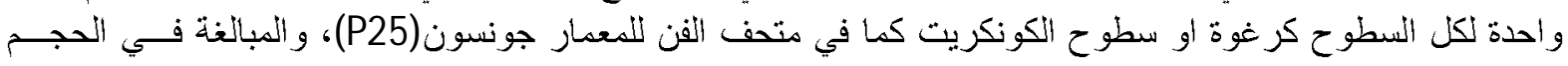

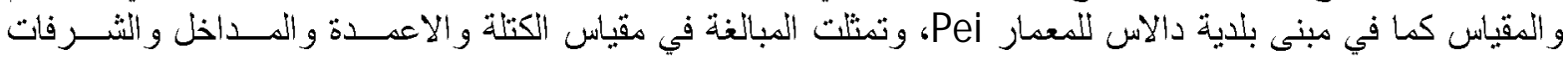




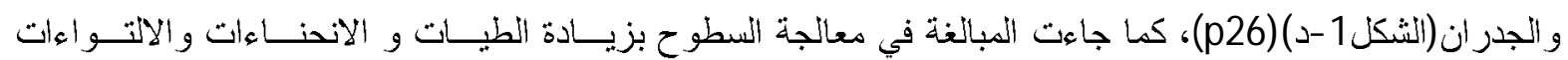

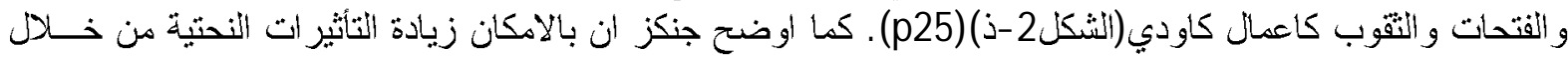

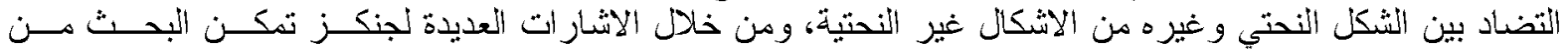

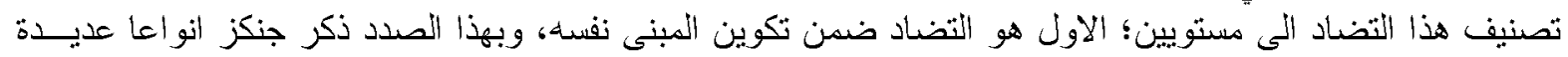

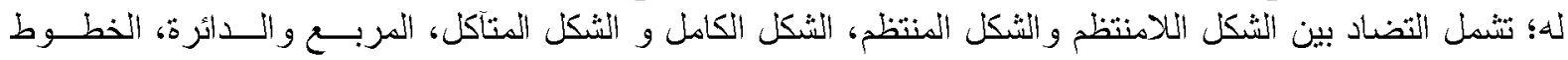

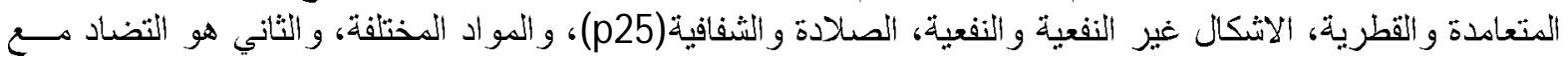

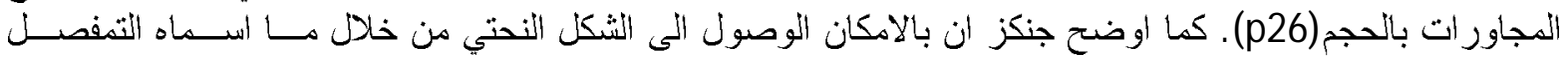

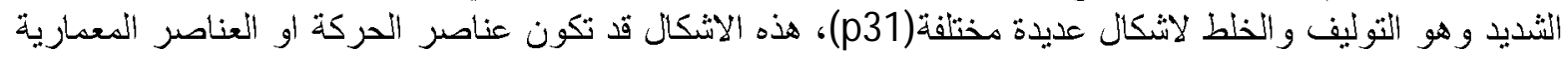

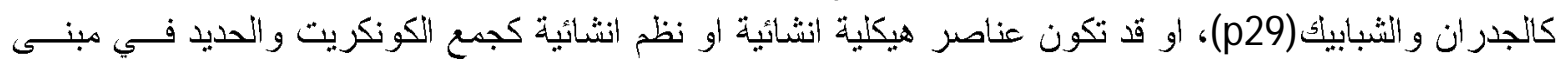

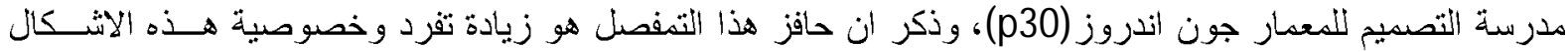

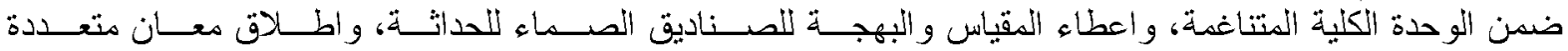

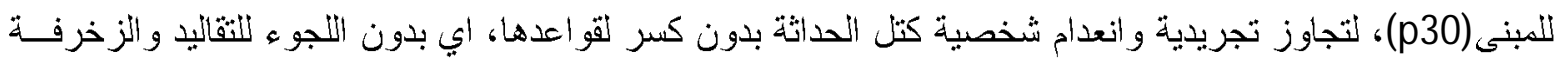

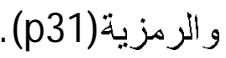

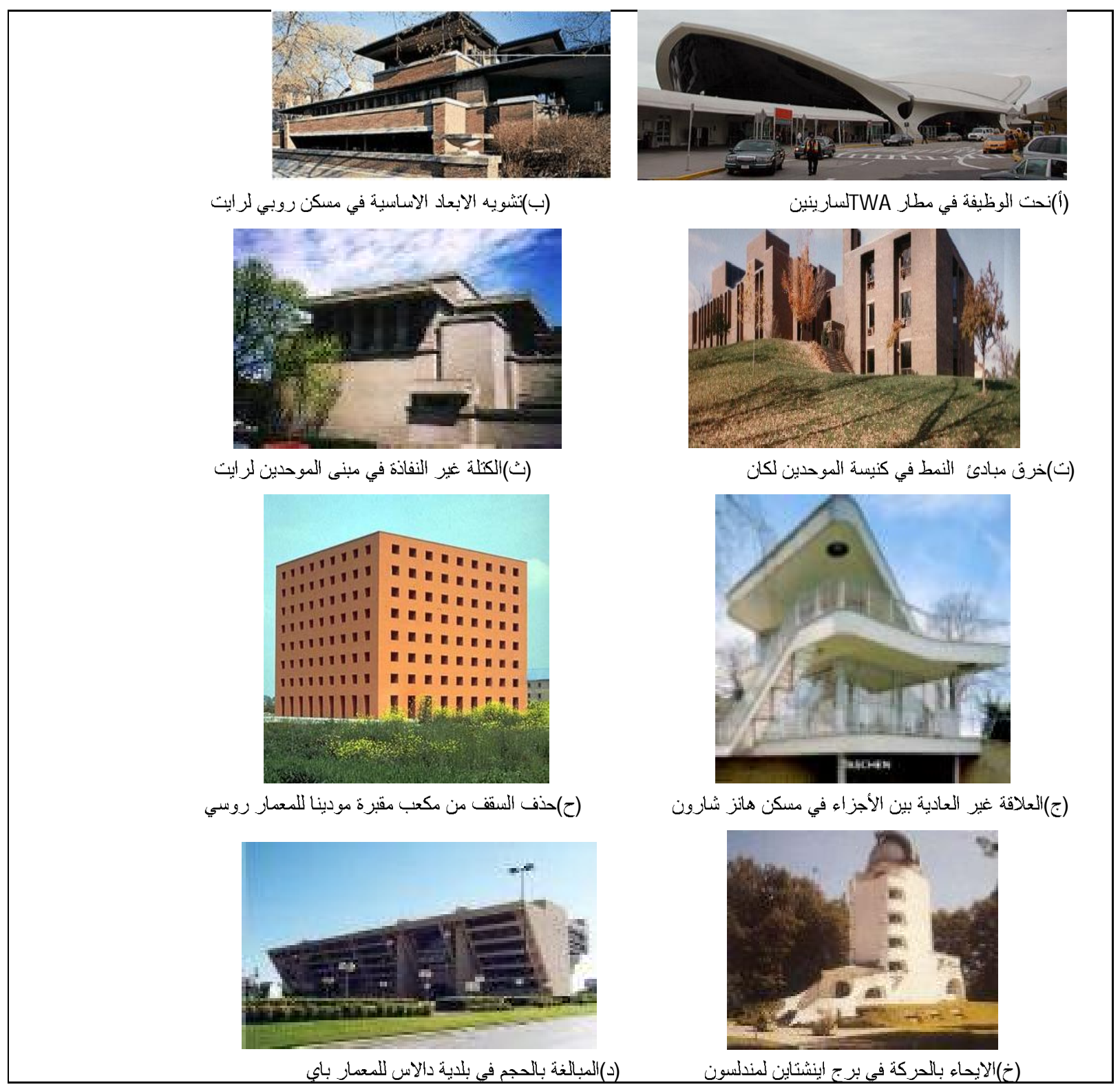

النشكل رقم ( 1 ) صور المشاريع الو اردة في الدراسات النسابقة 


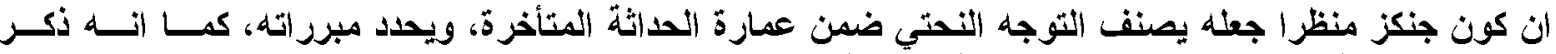
المصادر الغريبة للاشكال، فضلا عن المبالغة الثكلية والتضاد و التمفصل الثديد كوسائل للوصول ونئل لهذه الاشكال.

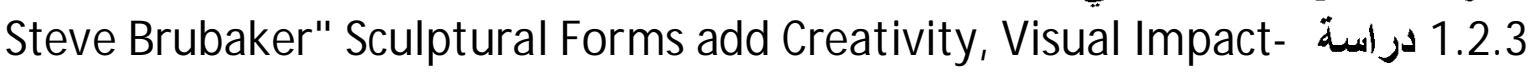 Article XII "}

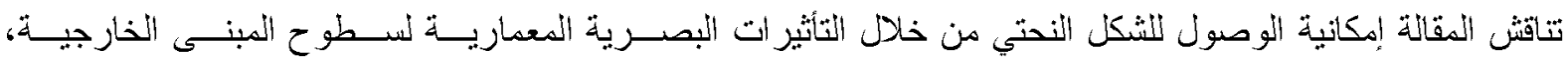

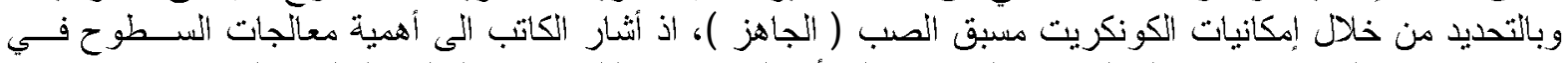

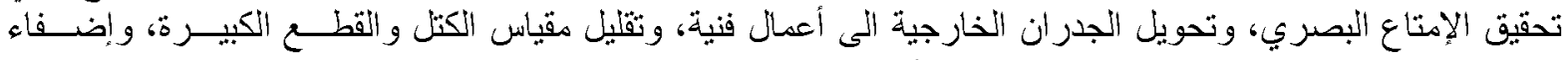

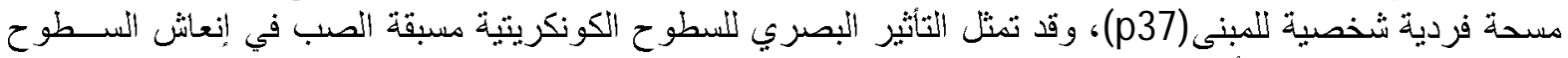

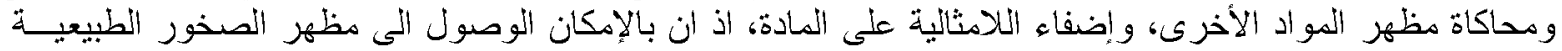

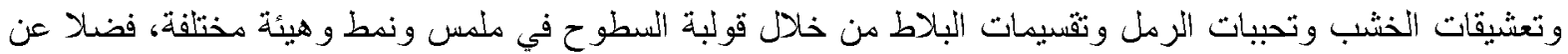

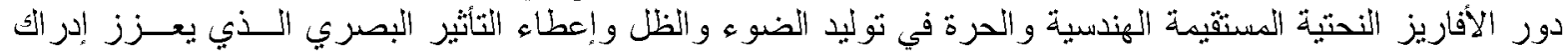

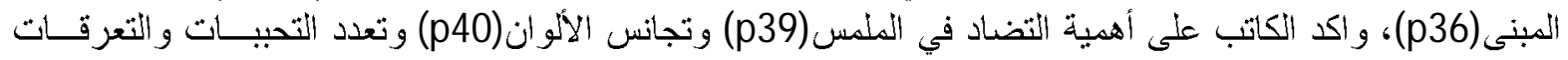
و الصبغات و الطبقات(p41) في إعطاء أداة للمقياس و اغناء السطوح بملمس المو اد و إضفاء التعبير الأنيق للمبنى كالخفة

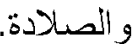
حدد برباكر احدى وسائل الوصول للشكل النحتي من خلال الخصائص الخارجية لسطوح كتل المبنى، واشار ايضا الى

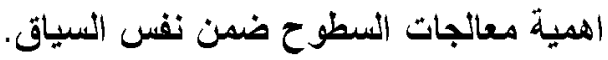

\section{3 دراسات عن العلاقة بين العمارة والنحت}

\section{Aruna D,Souza ,Tom M cDonough " Sculpture in the space of 1.3 .3 architecture " , 2000}

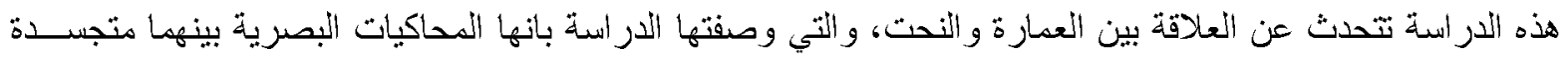

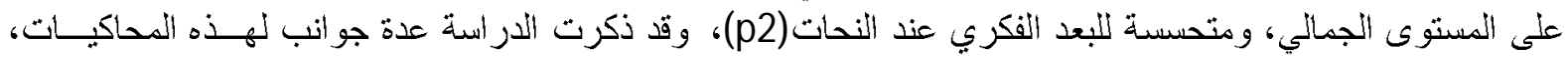

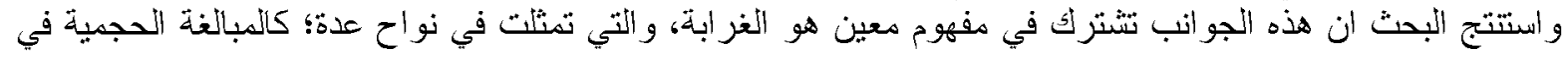

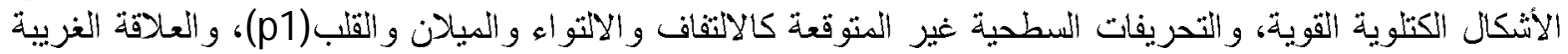

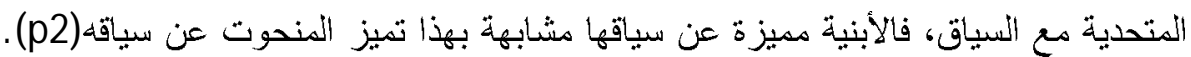

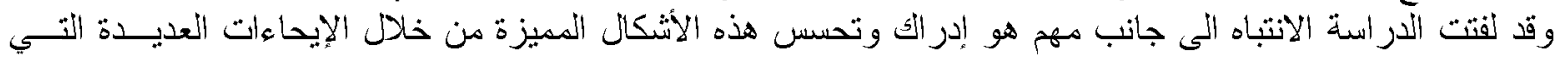

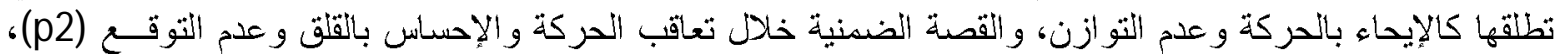

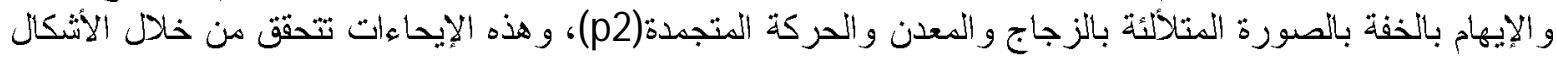

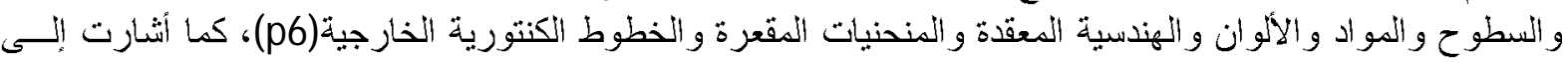

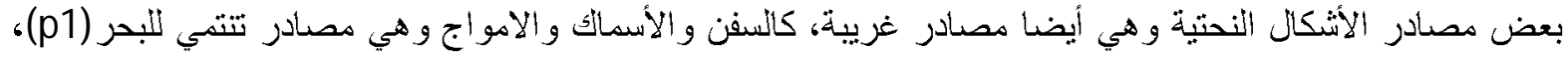

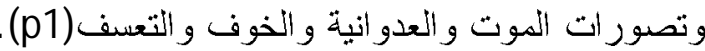

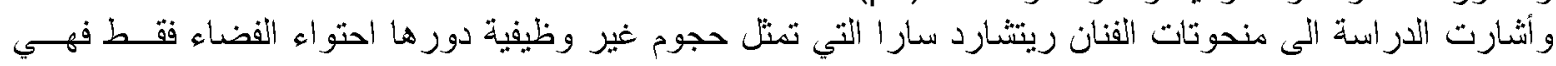

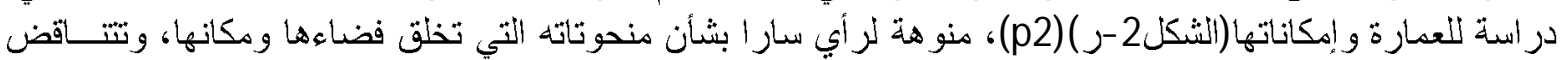

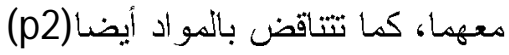

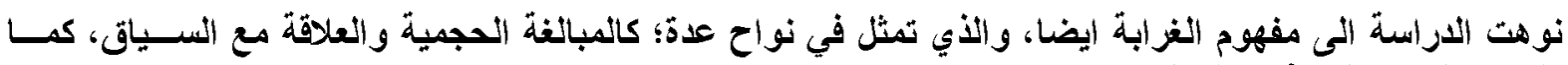
Philip Jodidio " Architecture : Art " , 2005 اشارت الخى الدرأك هذه الاشكال.

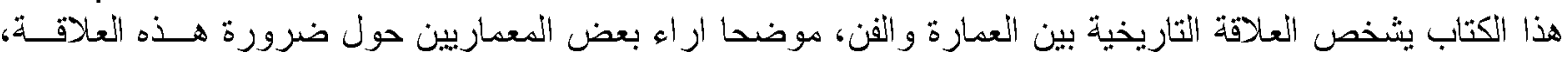

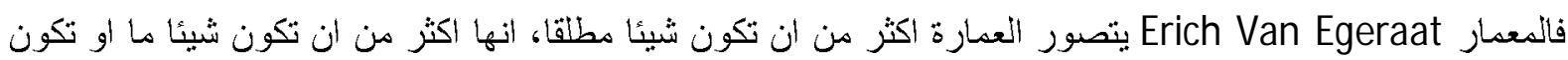

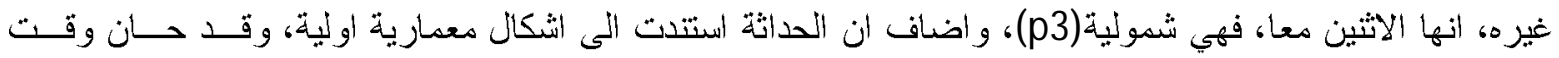

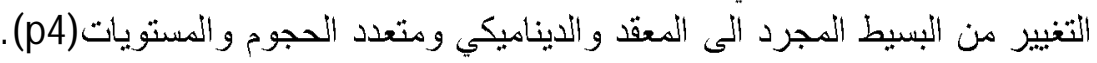




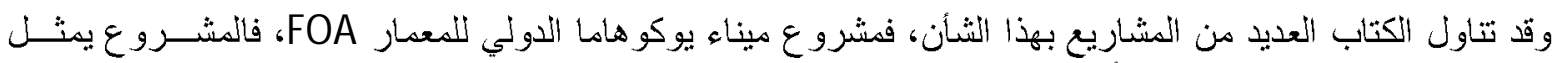

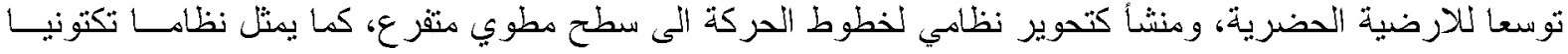

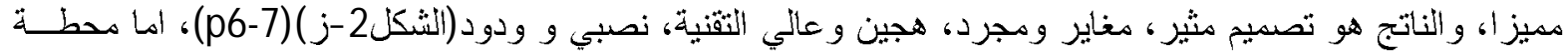

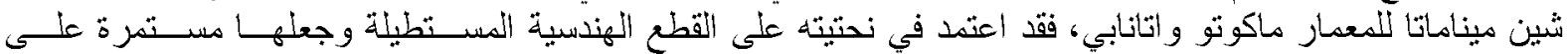

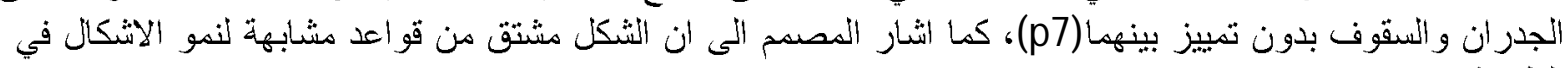
الطبيعة

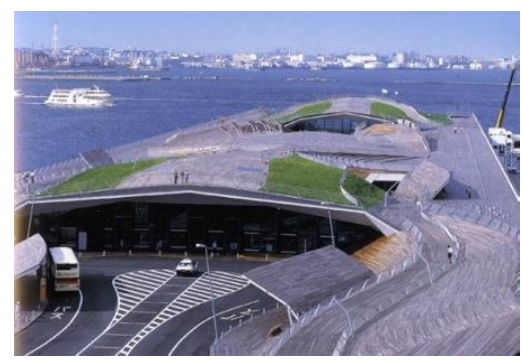

(ذ)خمويز نظامي لخطوط الحركة في ميناء بوكوهاما

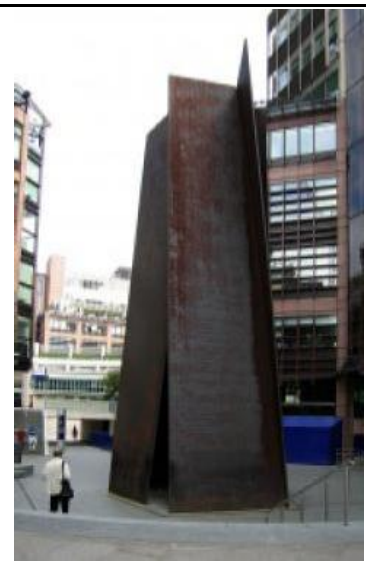

(ر) حجوم غير وثلفية لريتشارد سازرا

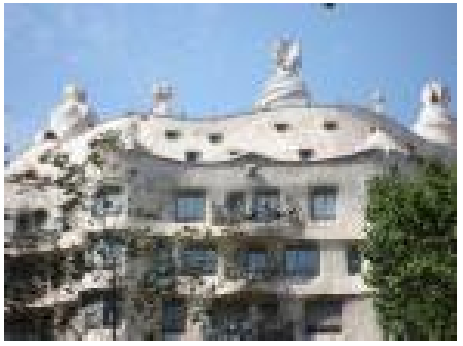

(ذ) الطبات و الانحناءات في اعمال كاوبدي

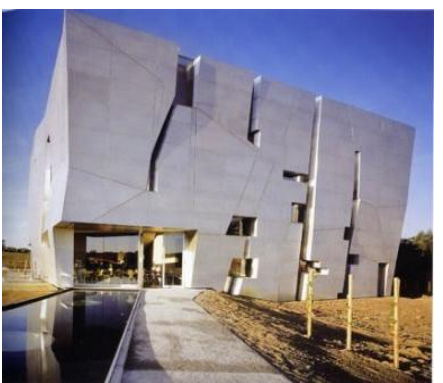

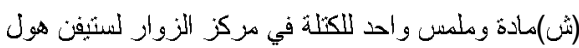

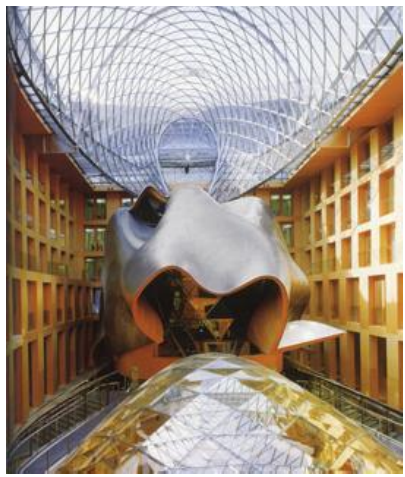

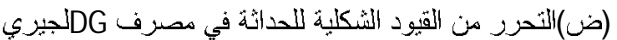

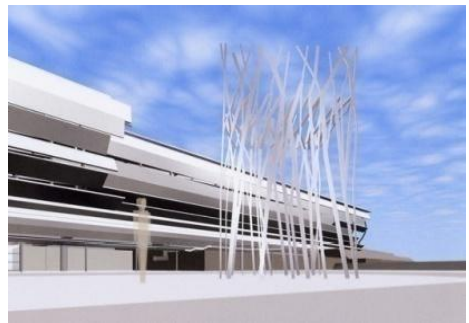

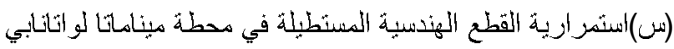

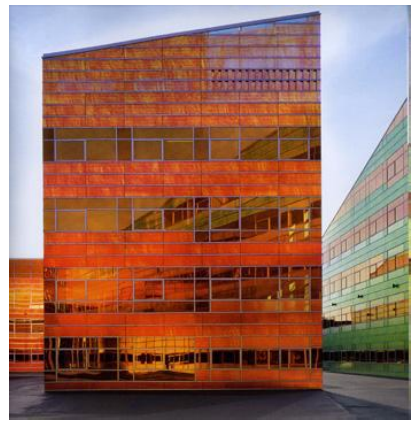

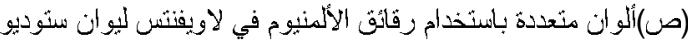

$$
\text { الثنكل رقم ( } 2 \text { ) صور المشاريع الو اردة في الدراسات السابقة }
$$

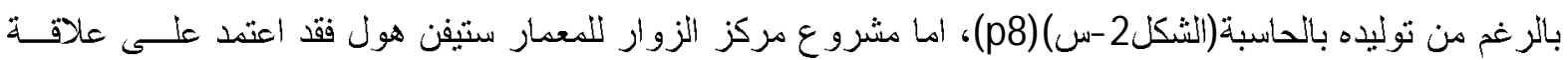

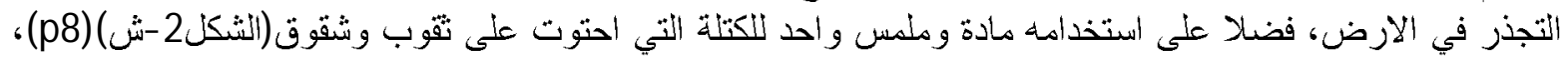

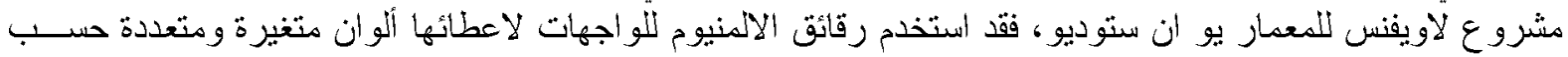

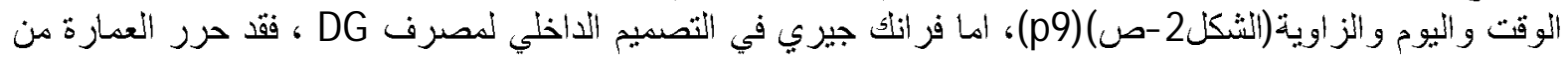




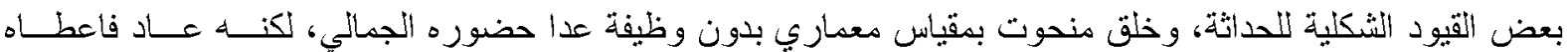

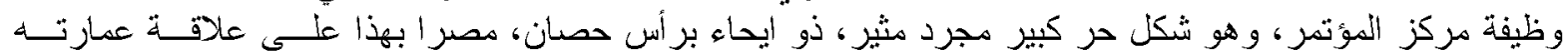

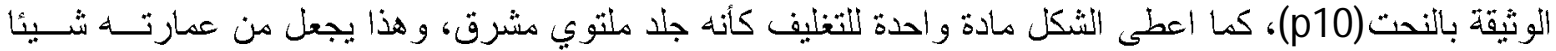

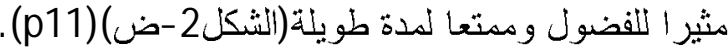
نوه جوديديو المى العديا من المفاهيم المرتبطة بالتوجه، كحافز المعمار ومصادر الثكاله و المعالجة الخارجية للكتـل وعلاقة المبند بالسياق.

\section{Sungur " Dialogues between Architecture and Sculpture " Elif ,2006}

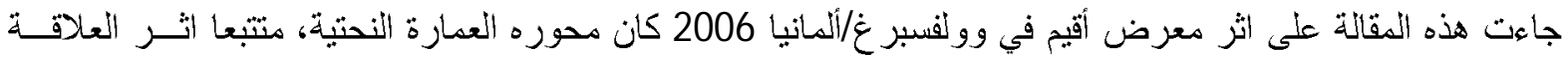

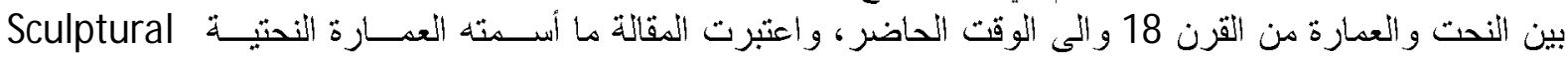
Architecture ، و اصطلحت عليه Archisculpture ، اعتبرته إستر اتيجية ووسيلة تسويقية فعالة للوظيفة الهعمارية

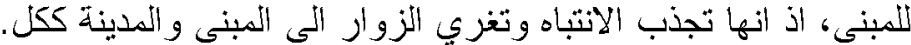

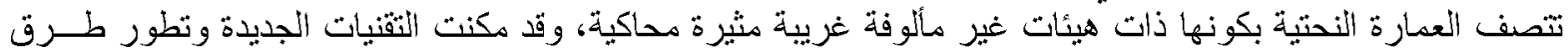

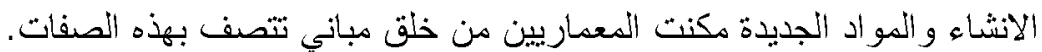

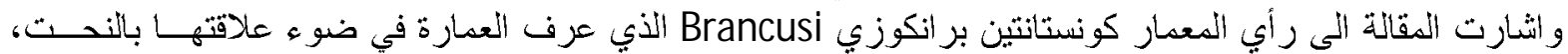

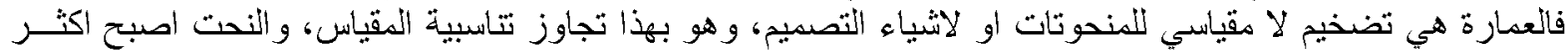

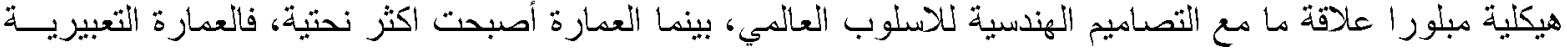

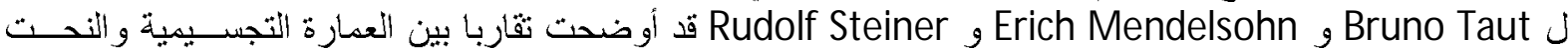

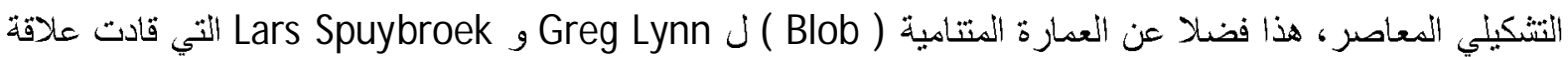

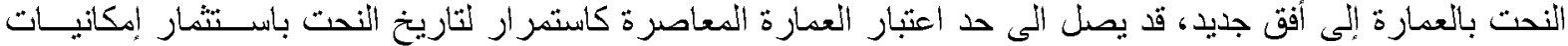

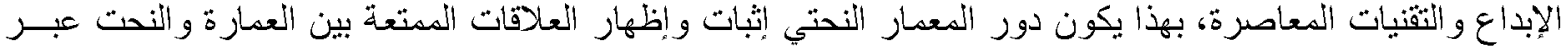
القزون الإن

اذن فقد عرفت المقالة العمارة النحتية وبينت مقوماتها، وأهميتها كإستر اتيجية، مشيزة بشكل غير مباشر الى مفاهيم

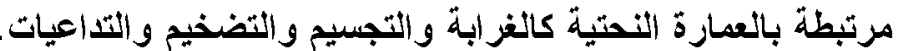

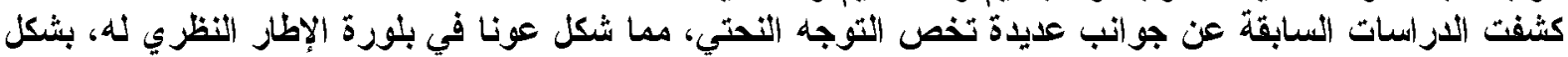

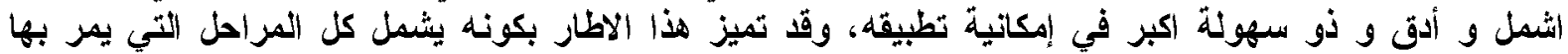
المبنى بدءا من حافز المعمار نحو هذا التوجه، وانتهاءا بادرالك المبنى النحتي من قبل المتلقي (الجدول رقي 1)

\section{4. الإطار النظري للتوجه النحتي في العمارة}

1.4 المفردة الأولى: حافز المعمار نحو التحتية : وهو الدافع والهوف الذي يجعل المعماريين بسعون نحو

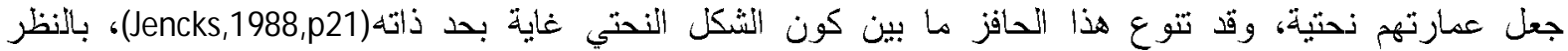

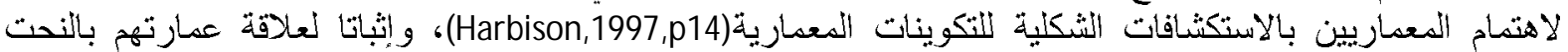

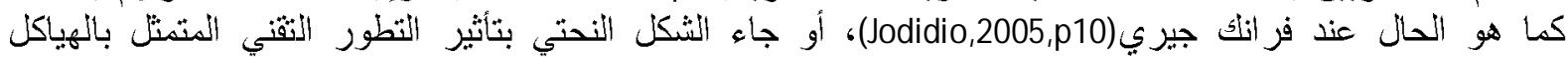

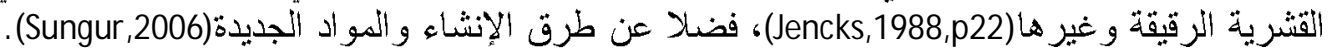

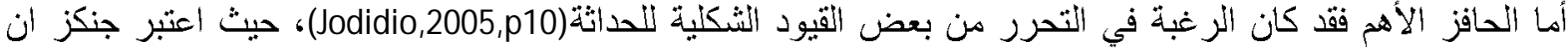

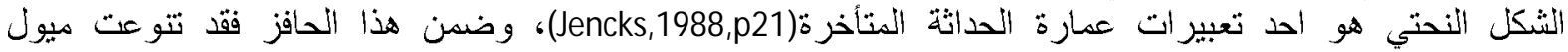

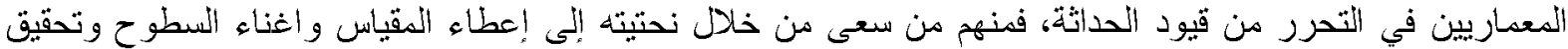

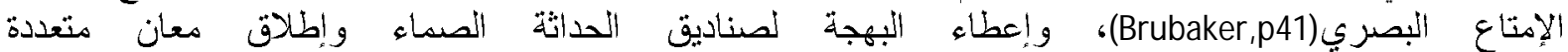
للمبنى(Jencks,1988,p30)، وجعل العمارة مثيرة للفضول وممتعة لأطول مدة (Jodidio,2005,p11)، كذلك سعى المعمار

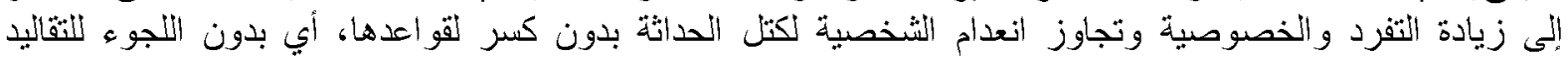

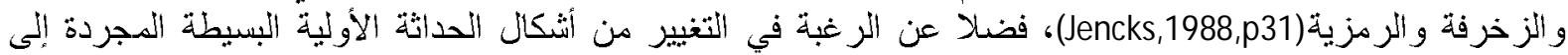
الأشكال المعقدة و الديناميكية وتعدد الحجوم و المستويات (Jodidio,2005,p4). 


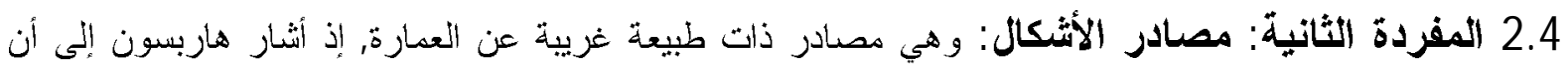

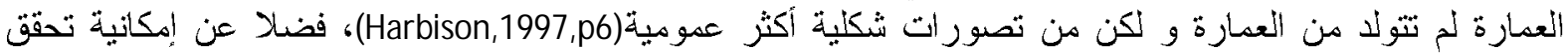

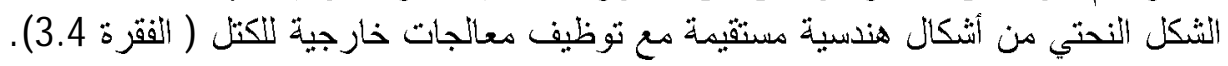

1.2 .4 طبيعة المصدر : مصادر الثكل النحتي متعددة منها ما هو عضوي كالجسد الحي و العضلات

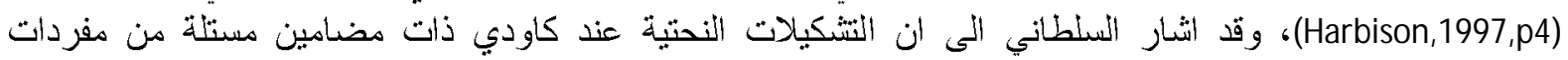

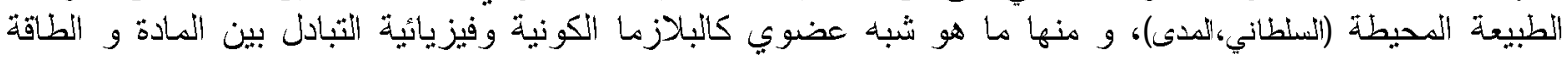

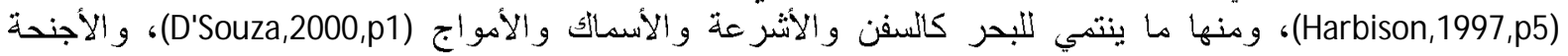

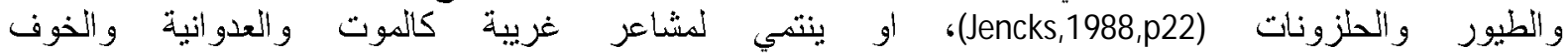
و التعسف(D'Souza,2000,p1)، و هناك مصادر غير متوقعة كحقل الذرة، والنظام التكتوني نلأرض(Jodidio,2005,p5-7)؛ فضلا عن إمكانية اثشتقاق الثكل من قو اعد مشابهة لنمو الأشكال في الطبيعة(Jodidio,2005,p8)، باستثمار امكانيات

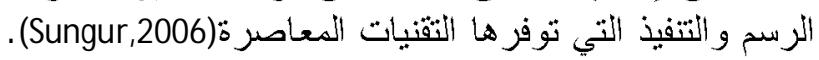

2.2.4 ارتباط المصدر بوظيفة المبنى : أشـار هـاربسون إلى وجود موقف محدد للعمارة النحتية من الوظيفة،

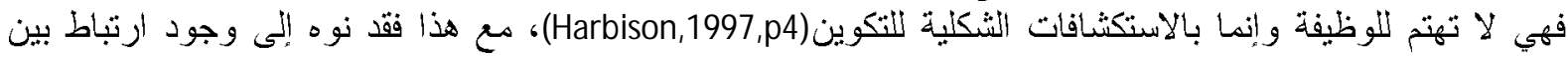

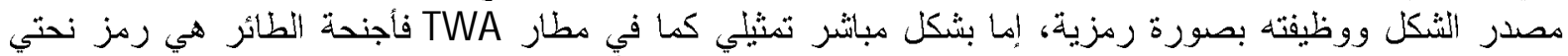

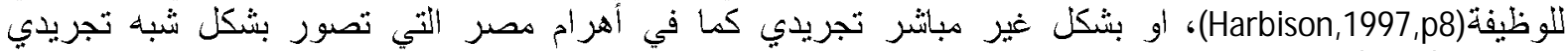

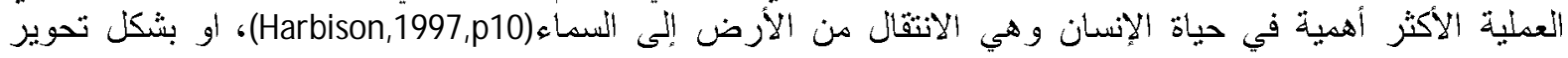

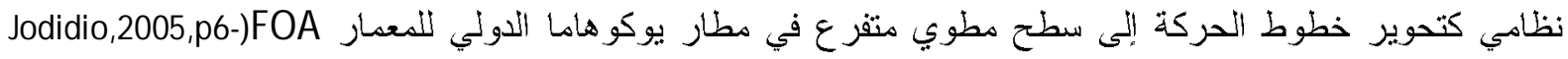

3.4 المفردة الثالثة: خصائص المعالجة الخارجية للكتل: وقد اثنار النسطاني الى ان التشكيل النحتي يتميز

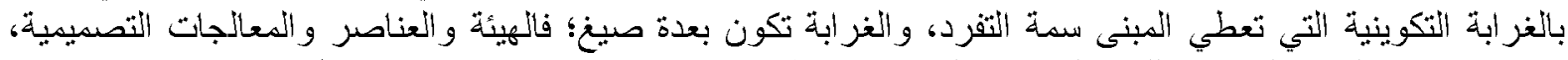

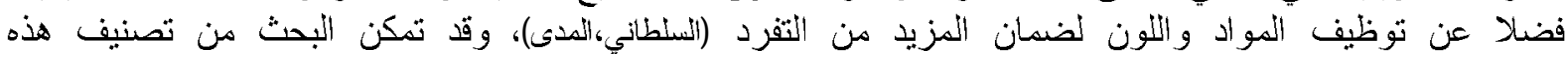

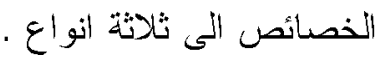

1.3 .4 التحريفات التهنسية : وهي التغييرات والتحويرات التي تجري على التكل في عدة مستويات منها؛

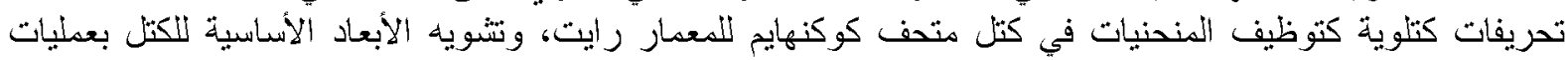

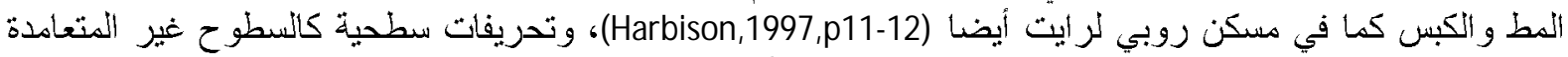

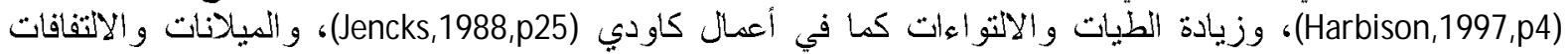
و القلب (D'Souza,2000,p1)؛ فضلا عن التحريفات التفصيلية كزيادة التقوب و الفتحات (Jencks,1988,p25)؛ و الثقوق

(Jodidio,2005,p8)

2.3.4 المبالغة الحجمية : وتمثلت بزيادة الحجم و المقياس للأشكال الكتلوية القوية للمبنى (D'Souza,2000,p1)؛ كما

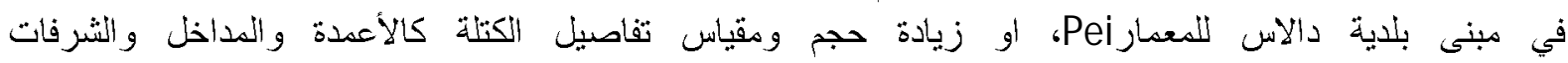
و الكدر ان (Jencks,1988,p22).

3.3 .4 التلاعبات الغلافية : وهي المعالجات المتميزة للغلاف الخارجي لكتل المبنى، وهي عديدة منها؛ استخدام

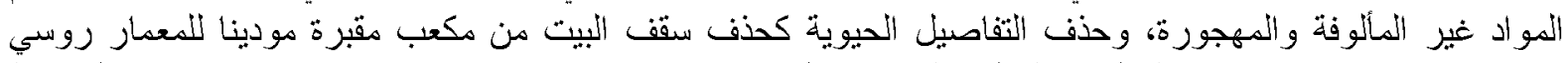

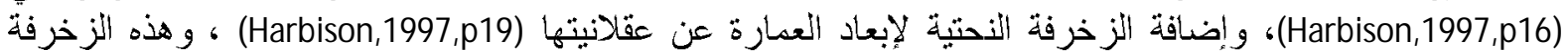

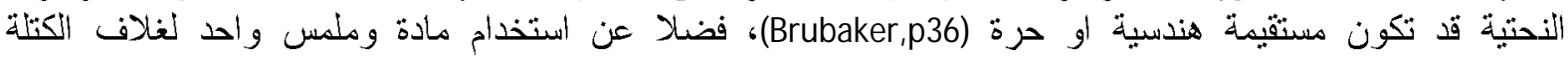

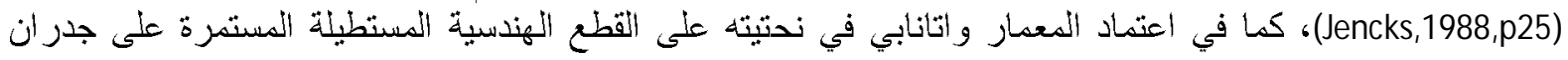

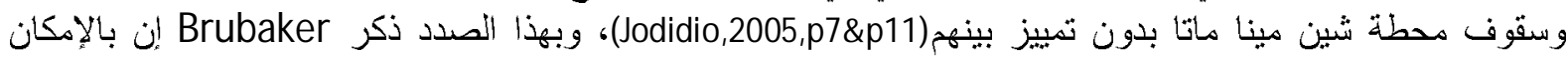

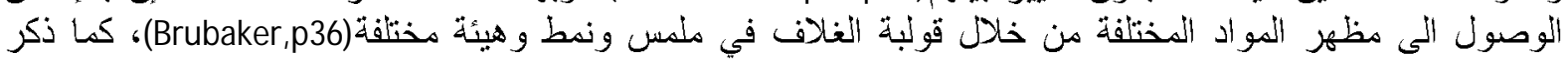
Jodidio 
4.4 المفردة الر ابعة: خصائص تجميع الكتل : ذكر Jodidio أن العمارة المرتبطة بالفن ذات أشكال معقدة

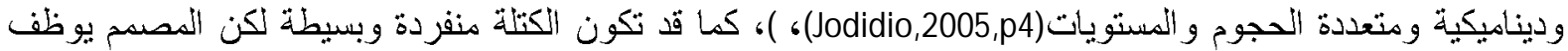

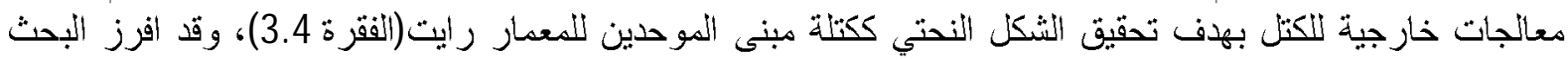

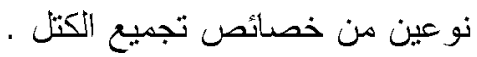

1.4.4 التضاد : وهو التتاقض بين خصائص كتل المبنى في عدة جوانب هنها؛ التضاد الثنكلي حسب انتظامية

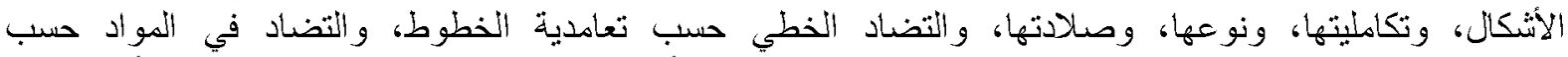

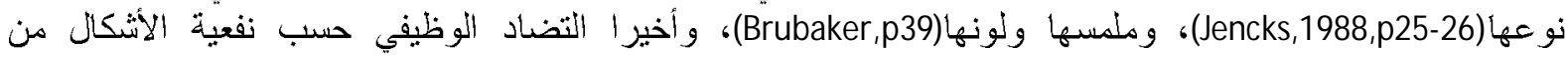
عدمها (Jencks,1988,p25) نوعه)

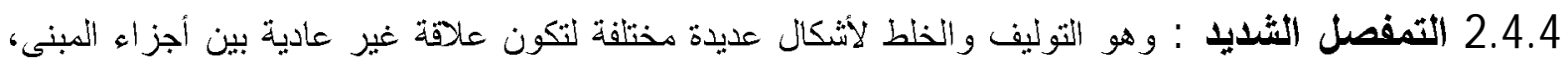

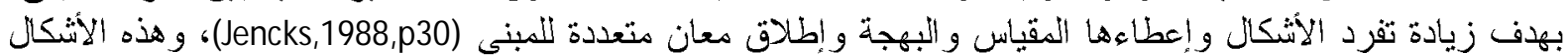

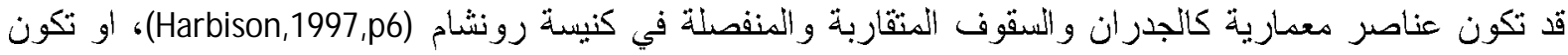

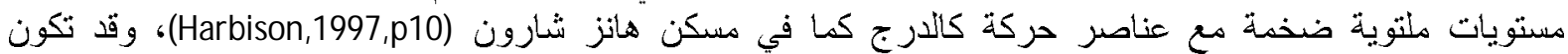

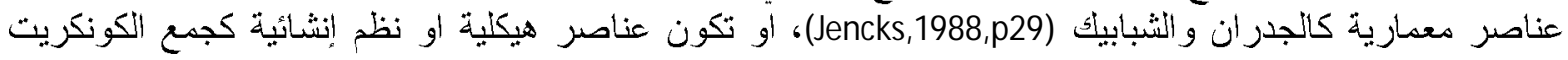
والحديد في مبنى مدرسة التصميم للمعمار اندروز (Jencks,1988,p30).

5.4 المفردة الخامسة: خرق المبادئ : وهو نقض ومخالفة بعض المسلمات المنطقية لمبادئ العمارة، وقد سعت

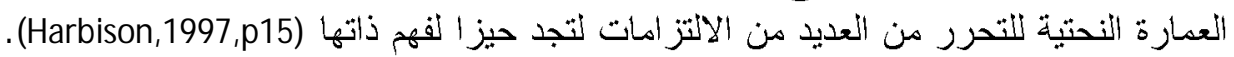

1.5 .4 خرق مبادئ النمط الوظيفي : وتمثلت بتغيير استخدام عناصر النمط ليدرك بوظيفة مختلفة عن أصله،

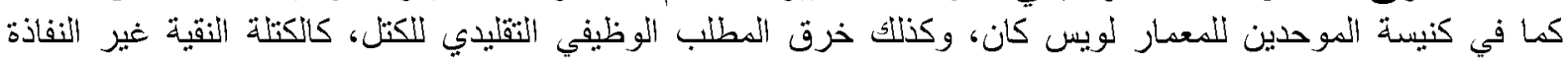
لمبنى الموحدين للمعمار رايت (Harbison,1997,p11).

2.5 .4 خرق مبادئ العلاقة مع السياق : محاولة من العمارة النحتية للاستلهام من النحت فقد سعت لختق علاقة

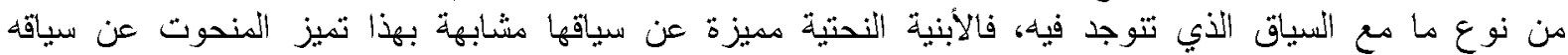

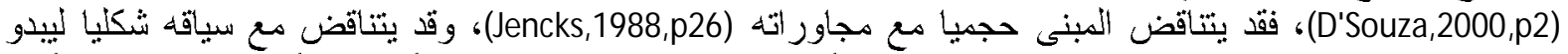

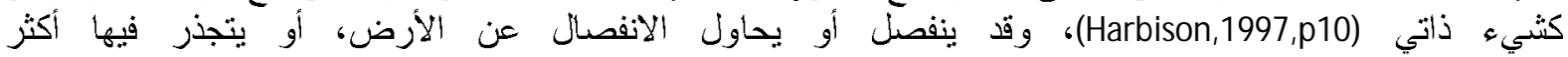
.(Harbison,1997,p7)

3.5.4 خرق المبادئ الثثكلية : إذ هناك بعض المبادئ الثكلية للمبنى، كحدود الانغلاقبة غبر الو اضحة للأشكال

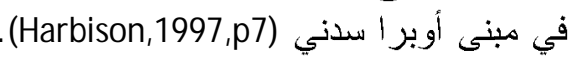

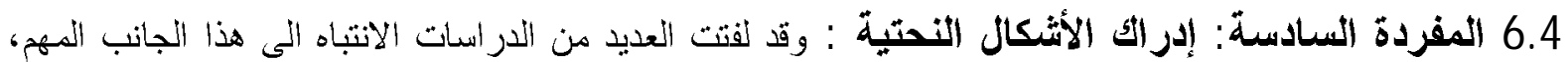

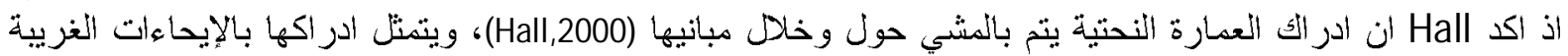

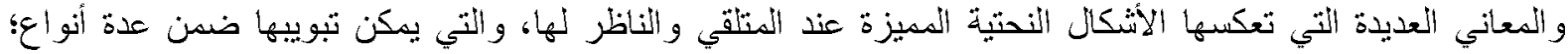

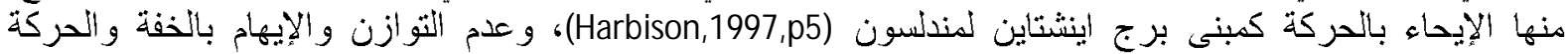

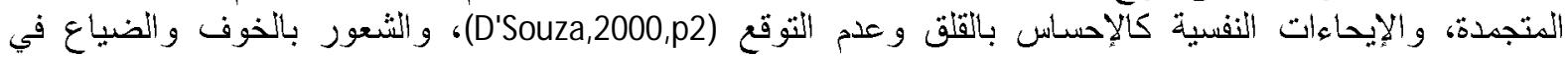

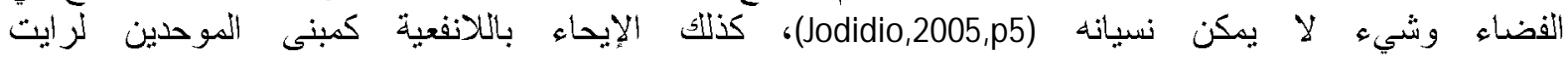
(Harbison,1997,p11)؛ و اللاعقلانية (Harbison,1997,p19)؛ فضلا عن الإيحاءات التجسيمية كمركز المؤتمر في

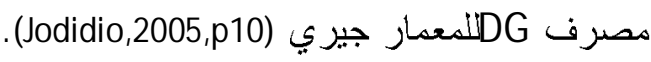

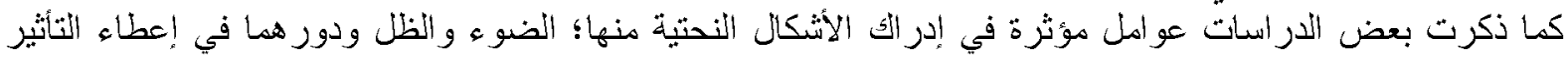

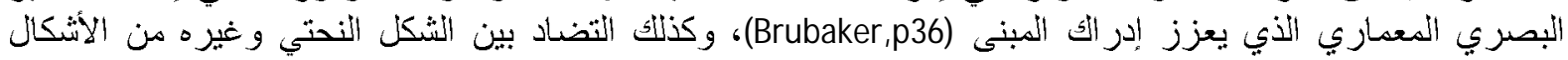
غير النحتية (Jencks,1988,p25). 


$$
\text { الجدول رقم ( } 1 \text { ) الإطار النظري لتوجه النحتية في العمارة }
$$

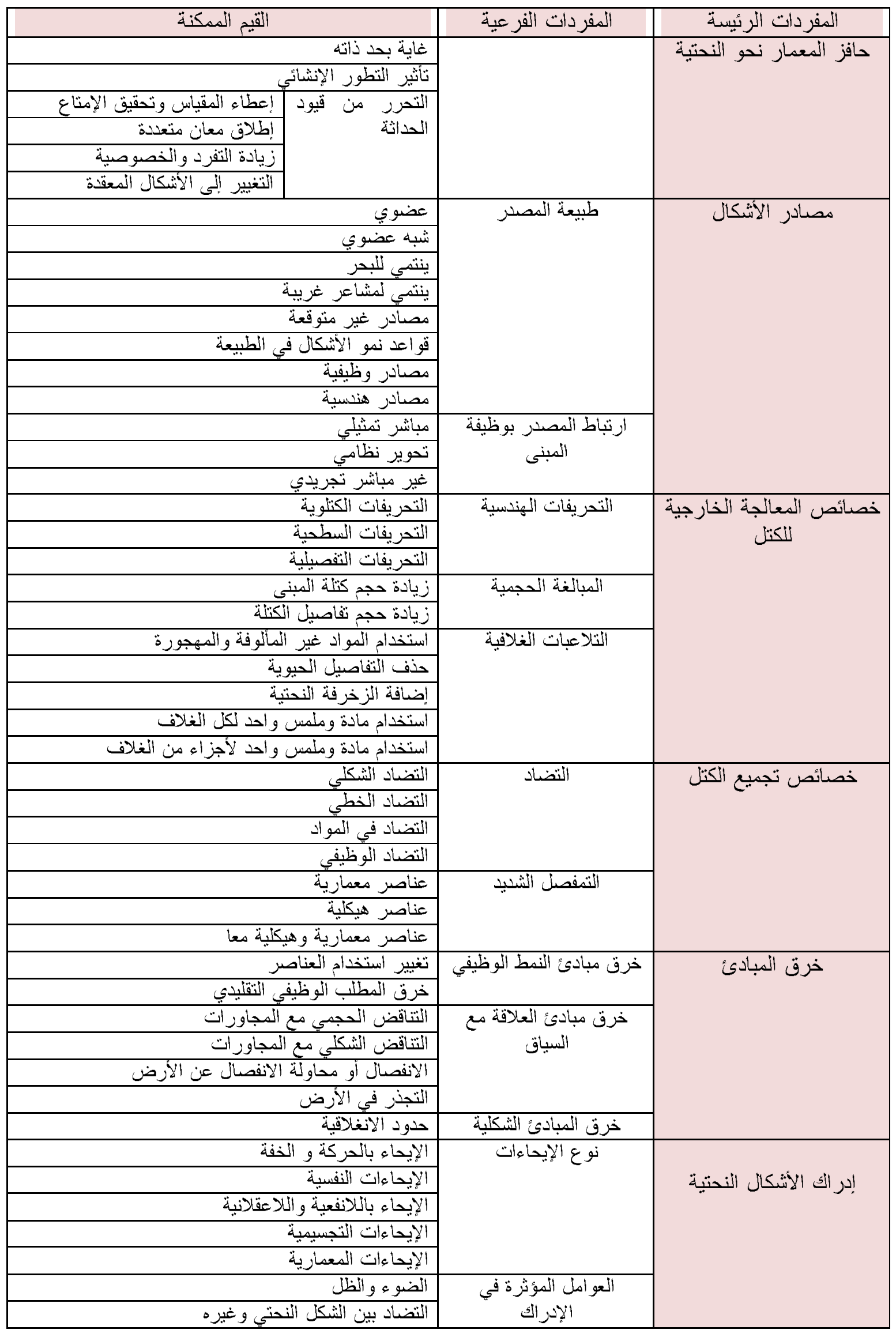


5. تطبيت الإطار النظري: يهدف النطبيق إلى البحث عن إمكانية وجود نمط معين لتحقيق التوجه النحتي في أعمال

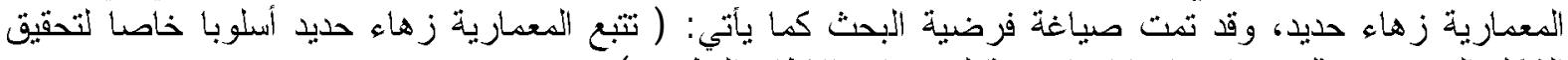

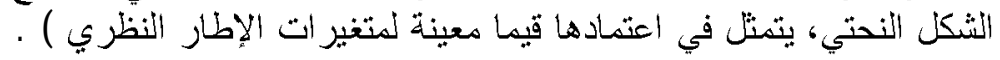

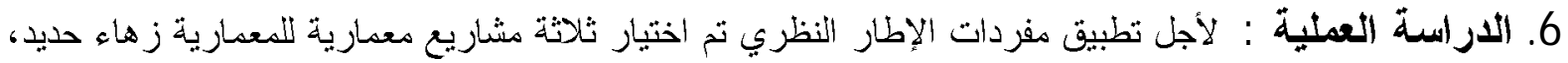

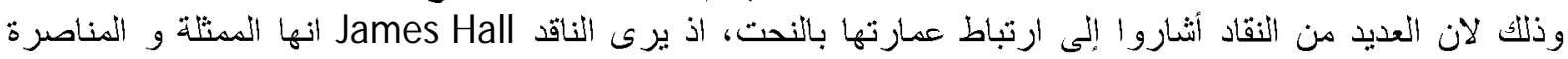

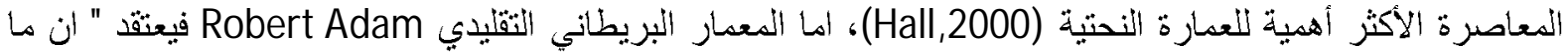

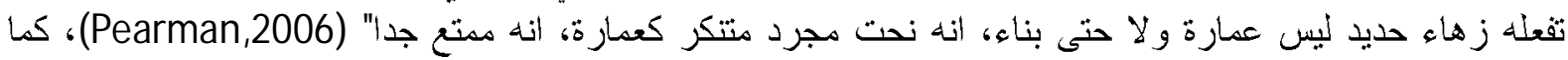

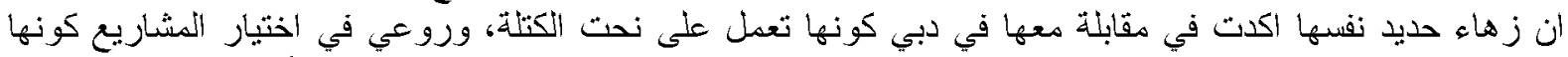

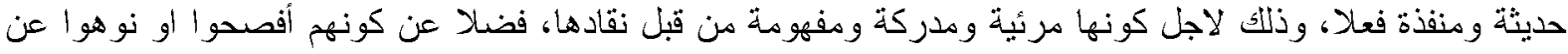

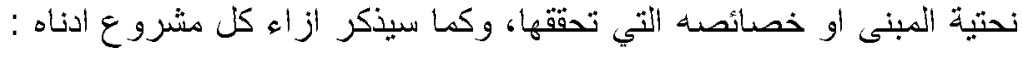

1- هشروع مركز العلوم في وولفسبورغ / أنمانيا /2005 / الثكل رقم(1) يعتبر المبنى كثيء نحتي (Pearson,2006,p78)، ينحت المبنى الفضـــاء المعهــاري الــديناميكي غيــر المسبوق (www.ces.de).

$$
\text { 2- مشروع معرض جسر زار اكوزا في زار اكوز / / اسبانيا /2008 / الثكل رقم(2) }
$$

WORLD ARCHITECTURE ) تقول زهاء حديد ( ان طموحنا باتجاه خلق هياكل معقدة وديناميكية مائعة )

(NEWS.com

3- مشروع مبنى BM W المركزي في لييزغ / المانيا /2005 / الشكل رقم(3)

تقول زهاء حديد ( في العمارة يجب ان نجرب الاشياء الجديدة، وهناك رغبة للوصول التى مبنى ذو ميوعـة

و تعقيد ) (Barreneche,2005,p86-90)

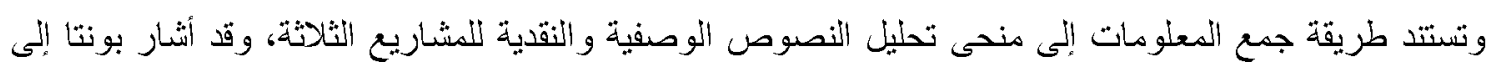

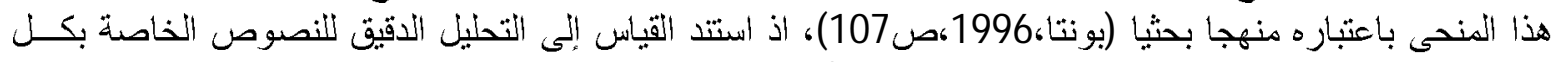

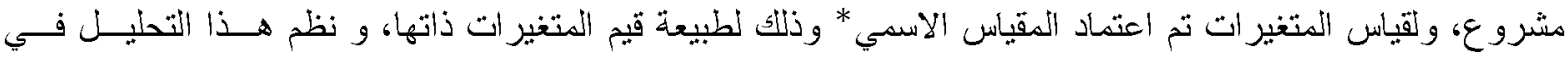

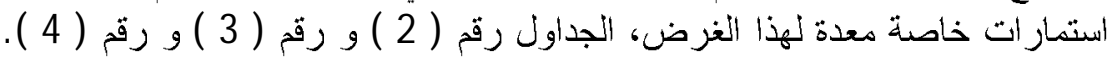

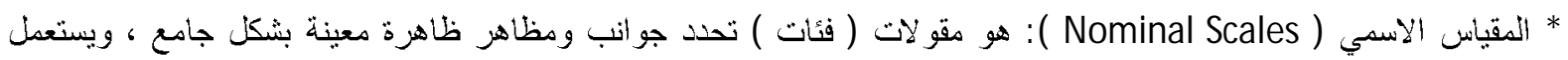

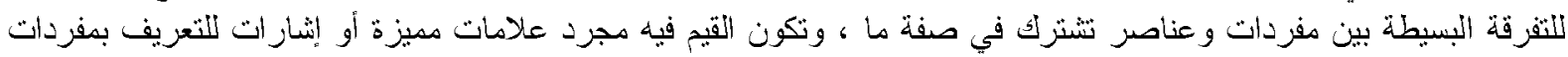

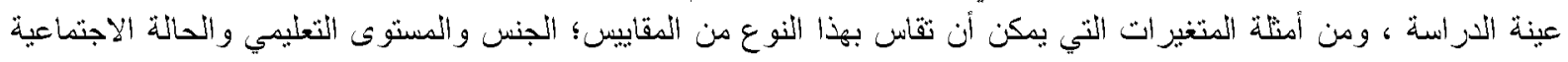



Al-Rafidain Engineering
Vol.19
No.1
February 2011
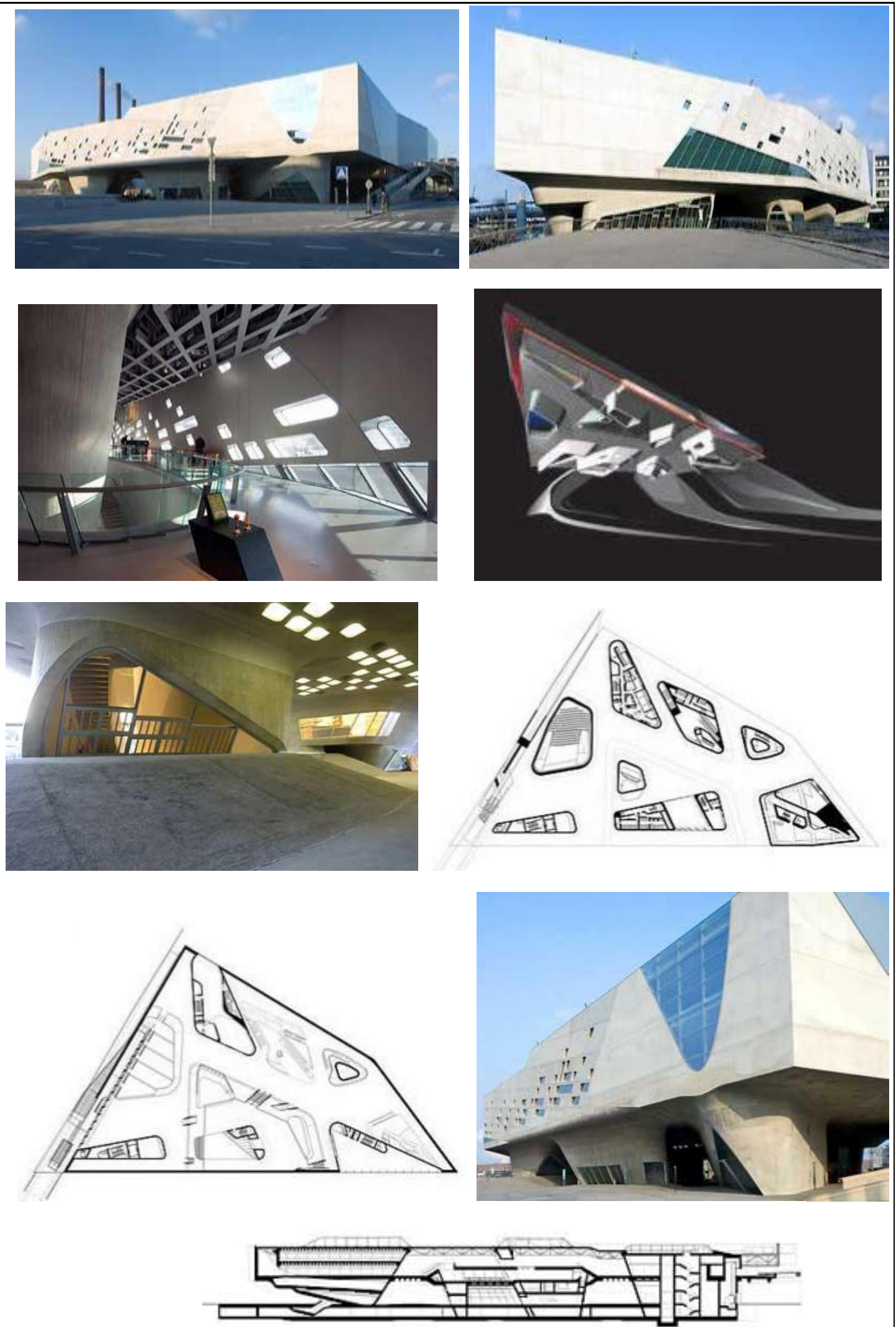

الثكل رقم ( 3 ) مشروع مركز العلوم في وولفسبور غ / ألمانيا / 2005 
ألدباغ: العمارة النحتية :تو جه زها حديد

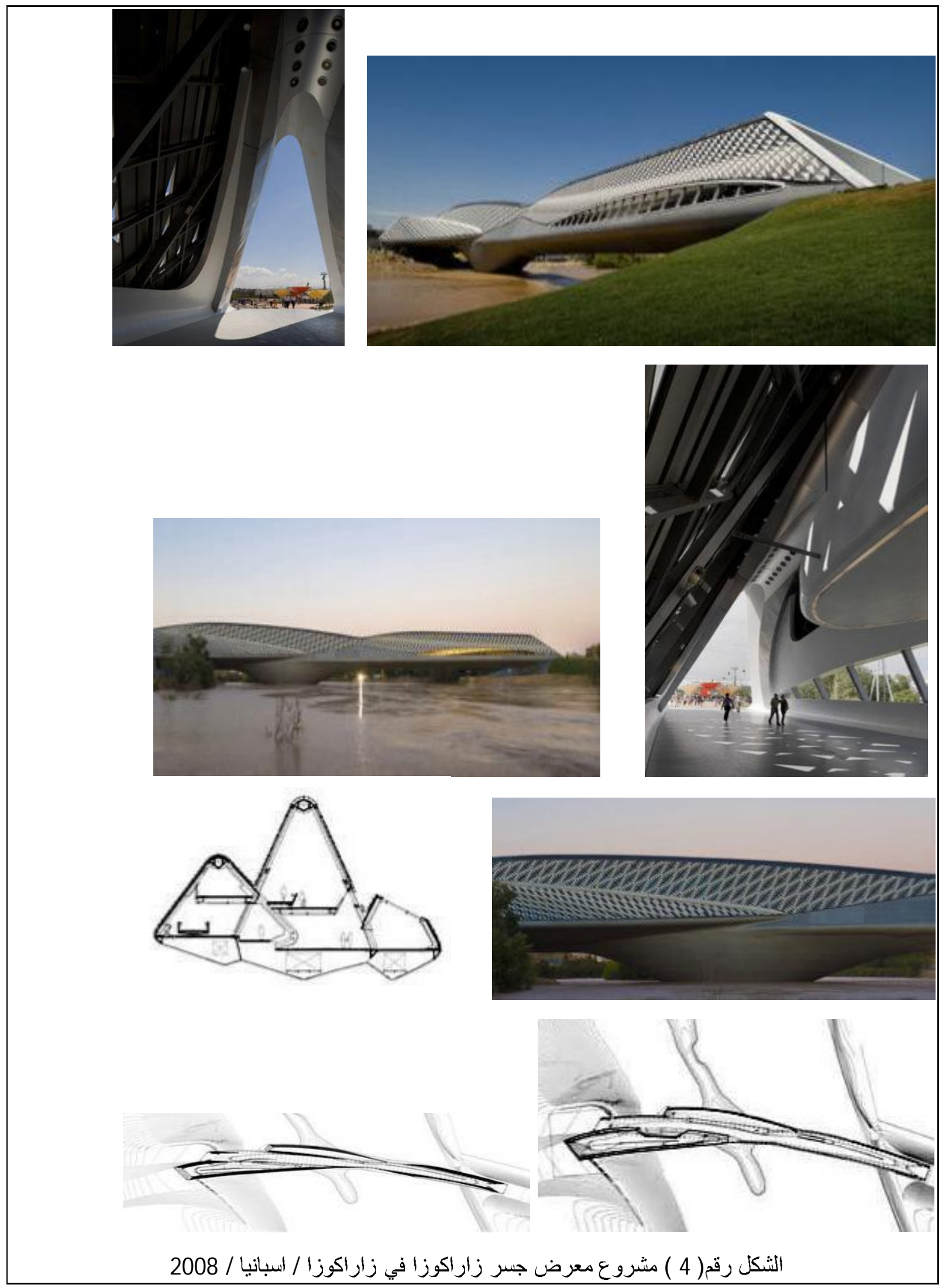



Al-Rafidain Engineering
Vol.19
No.1
February 2011

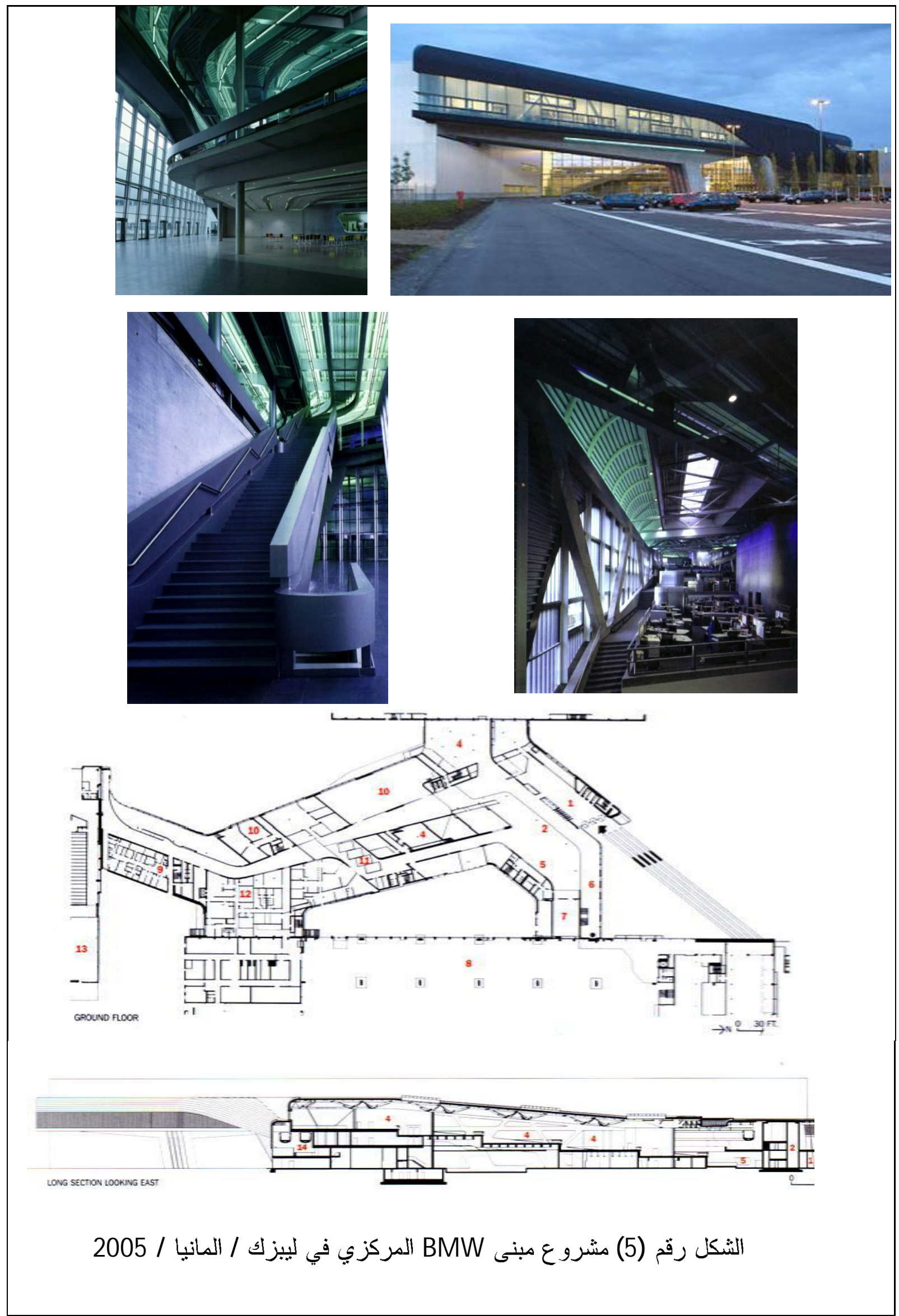


الجدول رقم ( 2 ) استمارة القياس لمشروع مركز العلوم في وولفسبور غ/ ألمانيا

\begin{tabular}{|c|c|c|c|}
\hline مصدر المعلوهات & القيم النمقانسة & المفردات الثرعية & الزئيريدة \\
\hline 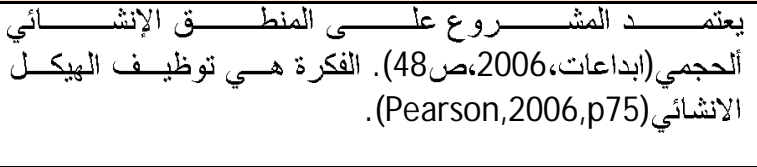 & تأتثير التطور الإنشائي & & المعمار \\
\hline فوقة (arcspace.com). & مصادر غيز متوقةت & طُ & 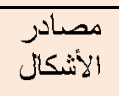 \\
\hline الملاحظة المباثنرة & غير مبانثر تجريدي & | بوتبفة المبنى المصنر & \\
\hline 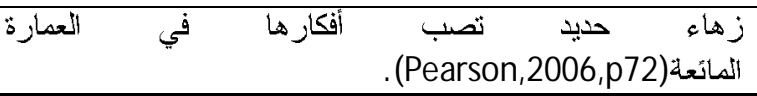 & التحريفات الكتلوية & الاتحريفات النهندسية & خصائص \\
\hline 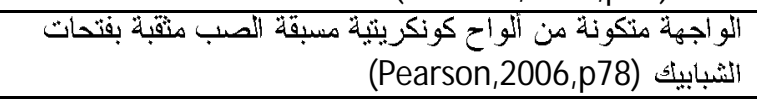 & التحريفات النسطية & & اللخارجية \\
\hline مثقبة بفتحات الثبابيك (Pearson,2006,p78) & التحريفات التفصيلية & & \\
\hline 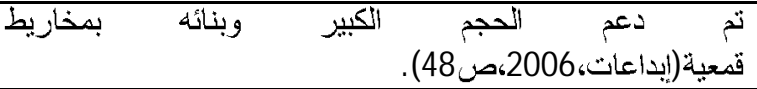 & زيادة حجم كتلة المبنى & المبالخة الحجمية & \\
\hline الملاحظة المبأثرة & 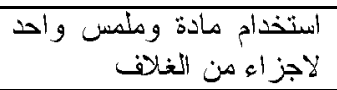 & التناعبات الغلافية & \\
\hline المبنى مقط بعناصر الو اجهة المتتوعة (wWW.ces.de) & التضاد في المو اث & الالتضاد & خصائص \\
\hline 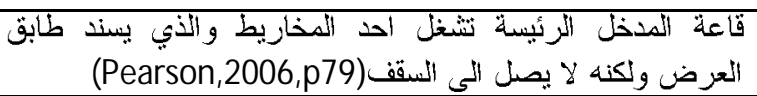 & معاصر معمازية و هيكلية & التصفصل الثنيد & تلجميع \\
\hline النيكل الانتائي اصبح برنامجا وظيفيا (Pearson,2006,p75). & 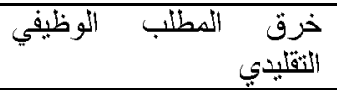 & خرف مبادئ النمط الوظيف & 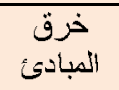 \\
\hline 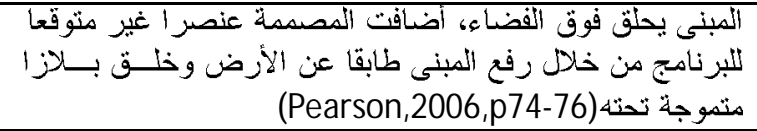 & 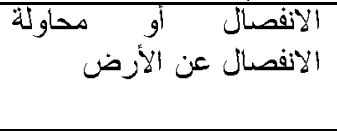 & خرق مبادئ النعلاقة & \\
\hline منذ متى يطير الكونكريتج يبنو المبنى كمركية فضائية هبطت & الإيحاء بالحركة و الخفة & نوع الإيحاءات & 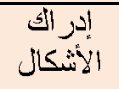 \\
\hline 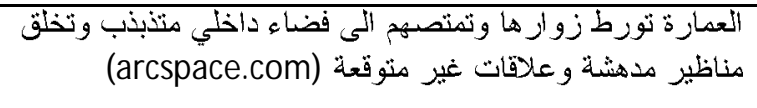 & الإيحاءات النفسية & & النحتية \\
\hline 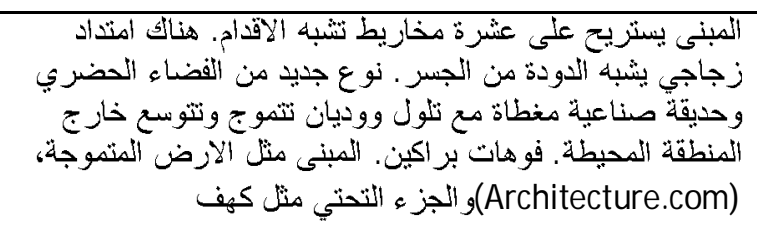 & الإيحاءات التجسيمية & & \\
\hline 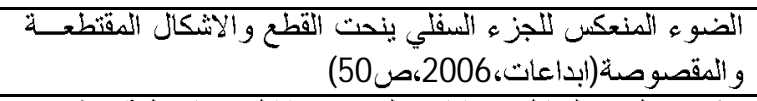 & الضوء و الظظل & الإدور الكل الموُثرة في & \\
\hline \multicolumn{3}{|c|}{ 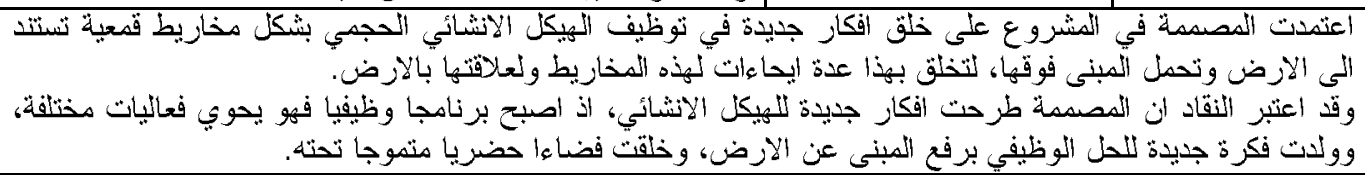 } & الباحتخ \\
\hline
\end{tabular}

الجدول رقم ( 3 ) استمارة القياس لمشروع معرض جسر زار اكوزا في زار اكوزا/ اسبانيا

\begin{tabular}{|c|c|c|c|}
\hline مصدر المعلؤوات & القيم المقاسة & المفردات الثرعية & 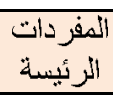 \\
\hline 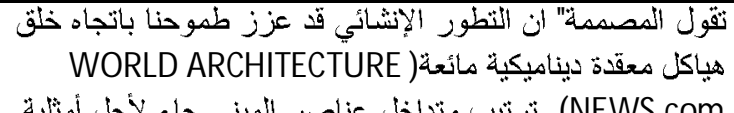 & تأثتر التطور الانشائي & & المعمارز \\
\hline
\end{tabular}




\begin{tabular}{|c|c|c|c|}
\hline الهيكل الإنتشائي(info@e-architect.co.uk) & & & |لأنحتية \\
\hline 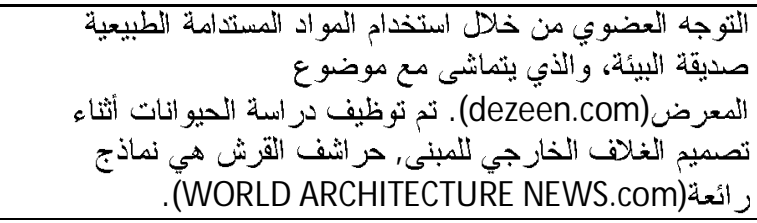 & عضوي & b & الأشكادز \\
\hline 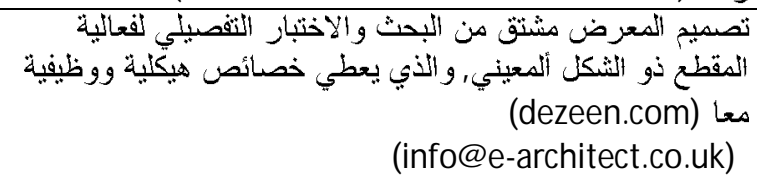 & مصادر غيز مثوقعة & & \\
\hline الملاحظة المبانثرة & ير نظامي & بوظيفة المبنى المصنز & \\
\hline التنكل الديناميكي للكنل, الحجوم المنحنية (arcspace.com) & التحريفات الكنلوية & التحريفات الكندسية & خصـائص \\
\hline 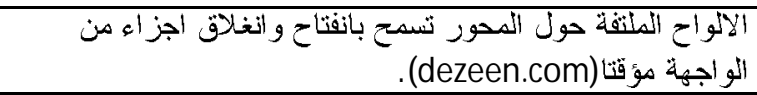 & التحريفات السطحية & & 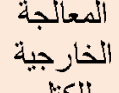 \\
\hline 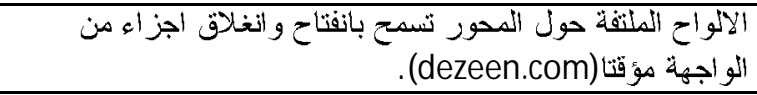 & التحريفات التنصيلية & & \\
\hline يكدف ترتيب التزون لتضخيم مقطع الجسر عندما يكون البحر & زيادة حجم كتلة المبنى & المبالغة الحجمية & \\
\hline النهر و المعرض الكييرة في المستوى النسفلي تسمح بالاتصال البصري مع & زيادة حجم تفاصيل الكتلة & & \\
\hline 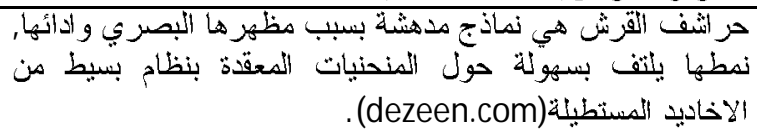 & استخدام المو أد غير الْمألْوفة & التلاعبات الخلافية & \\
\hline 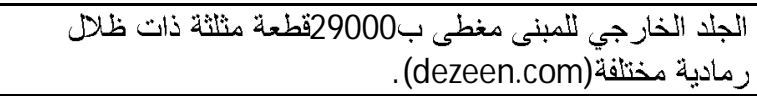 & 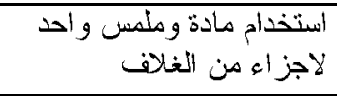 & & \\
\hline وانغلاقيات مكانية معال المبعة اشياء(قزون) التي تمنل عناصر هيكلية & معاصر معمارية وهيكلية & الأتمفصل النشّيد & خصائصن \\
\hline 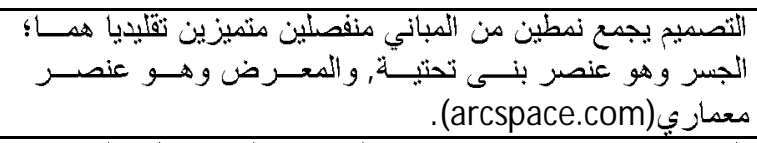 & خزتئن المطلب الوظيفي & خرق مبادئ النمطي & 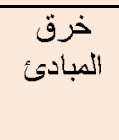 \\
\hline 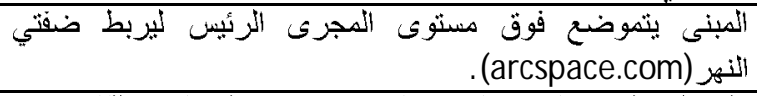 & الانفصال أو محاولن الأرض & خرف مبادث النعلاثة & \\
\hline 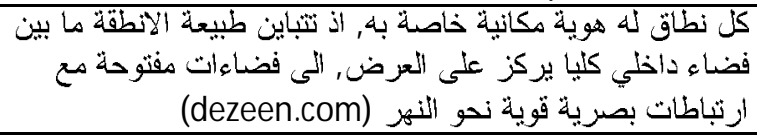 & حدو= الانغلاقية & خرف & \\
\hline 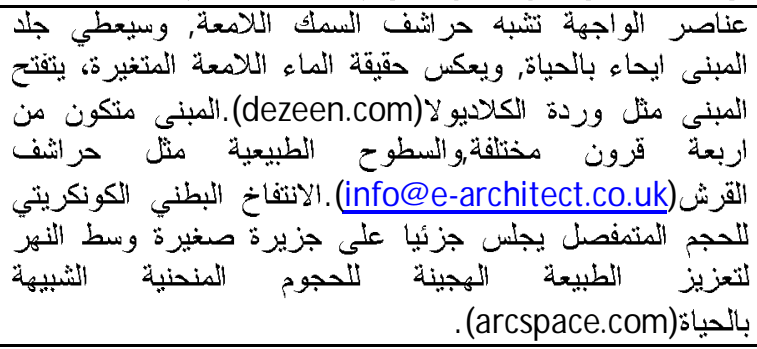 & الإيحاءات التجنيمية & نوع الإيحاءات & 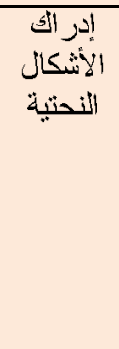 \\
\hline 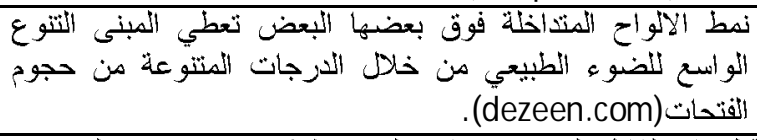 & الضو هو الظلّ & الإندو الكل المؤثرة في & \\
\hline \multicolumn{3}{|c|}{ 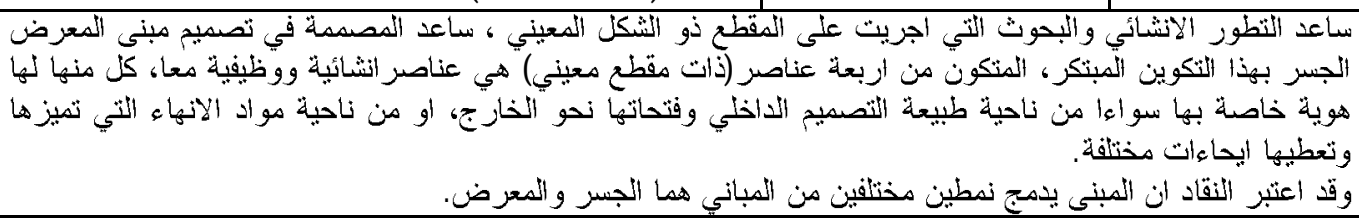 } & الباحتى \\
\hline
\end{tabular}


الجدول رقم ( 4 ) استمار ات القياس لمثروع مبنى BMW المركزي في لييز / المانيا

\begin{tabular}{|c|c|c|c|}
\hline مصدر المعلومات & القيم المقاسة & المفردات الثرعية & المفرِات \\
\hline 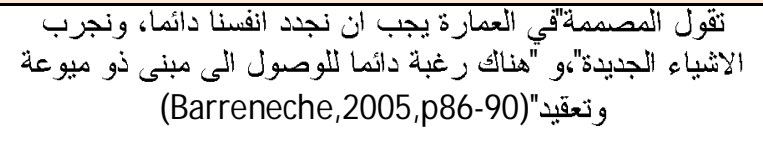 & غاية بحد ذاته & & المعمار \\
\hline 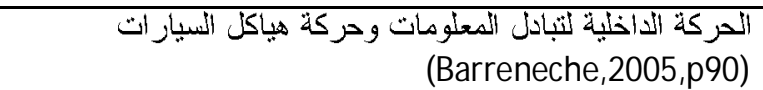 & مصـادر وظيفية & طبيعة" ألمصدر & \multirow[t]{2}{*}{ الأشكادل } \\
\hline 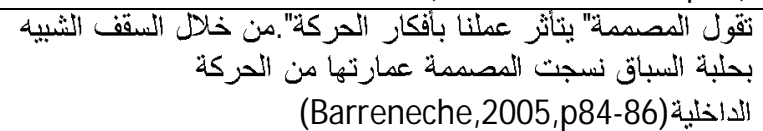 & تحوير نظامي & ارتباطة المبنى المصنز & \\
\hline 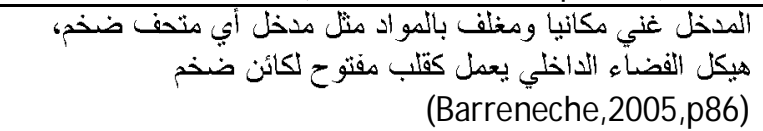 & زيادة حجم تفاصيل الكنتلة & المبالذة الحجمية & \multirow{2}{*}{ الخصائصة } \\
\hline الملاحظة المباثشرة & 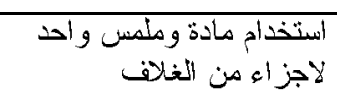 & التلاعبات الغلافية & \\
\hline انستخدام اللو نين الاززق و الابيض كتل المبنى & التضاد في المو ادي & التضاد & \multirow{2}{*}{ خصدائصن } \\
\hline 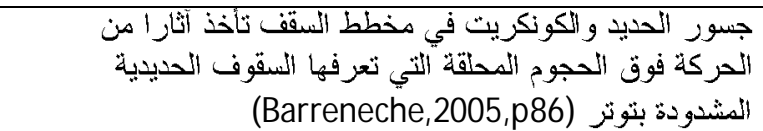 & معاصر معمارية وهيكلية & التمفصل الثشيد & \\
\hline 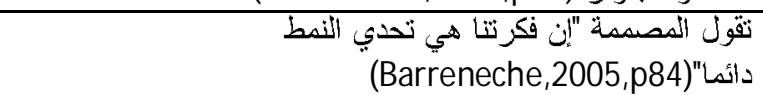 & خزق النقليدي المطنب الوظيفي & خرق مبانئ النمطي & \multirow[t]{2}{*}{ 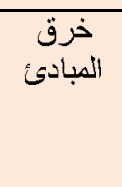 } \\
\hline 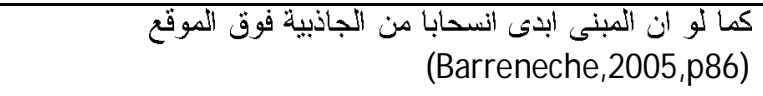 & الالانفصال أو عن الأرضل & خرق مباديق المعلاقة & \\
\hline 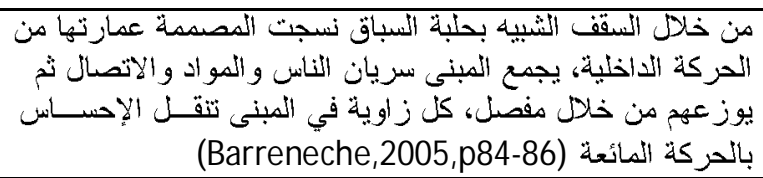 & الإيحاء بالحركة و الخفة & \multirow[t]{3}{*}{ نوع الإيحاءات } & \multirow[t]{4}{*}{ الأنسكال } \\
\hline 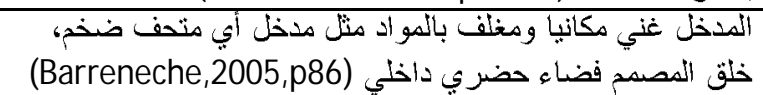 & الإيحاءات المعمارية & & \\
\hline هيكل الفضاء الثاخلي يعمل كقلب مفتوح لكائن ضخم & الإيحاءات التجسيمبة & & \\
\hline 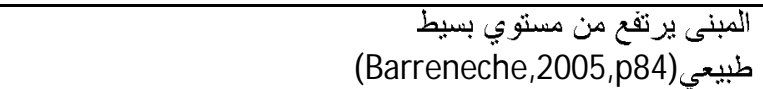 & والتضاد بين الثنكل النحتي & الإِدر الكل المؤثرة في & \\
\hline 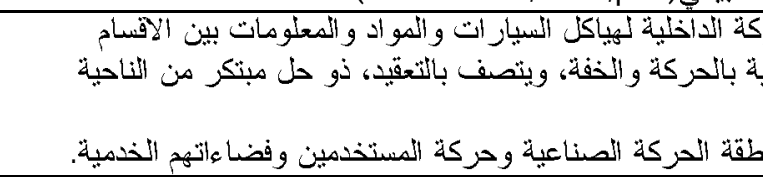 & 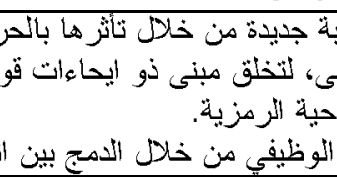 & 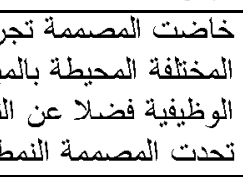 & مستخلص \\
\hline
\end{tabular}

\section{7. - 2 - ائج الار اسة العملية}

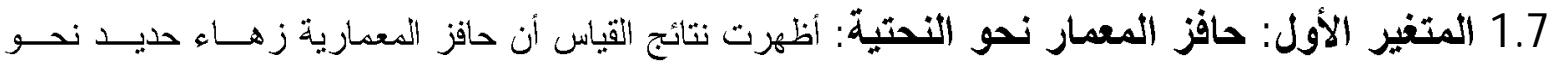

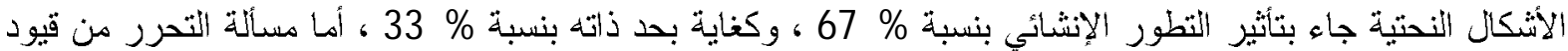
الحداثة فلم تشكل حافز الديها. 2.7 المتغير الثاني: مصادر الأثكال:

1.2 .7 طبيعة المصدر : أظهرت نتائج القياس أن طبيعة مصدر الأشكال عند زهاء حديد غير متوقعة بنسبة \% 50 ، بينما المصادر العضوية والوظيفية جاءت بنسبة \% 25 لكل منها. 


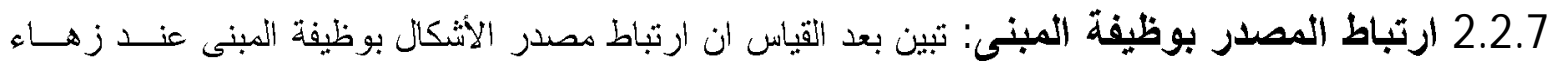

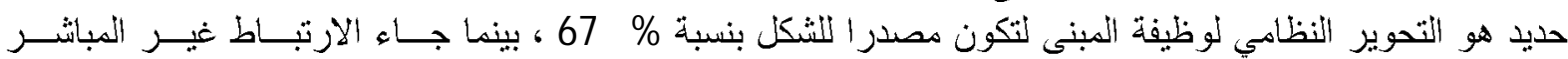
التجريدي للنشكل بنسبة 33 .

3.7 المتفير الثالث: خصائص المعالجة الخارجية للكتل: أظهرت نتائج القياس أن الخاصية التي تركز علئها

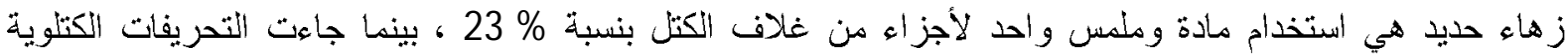

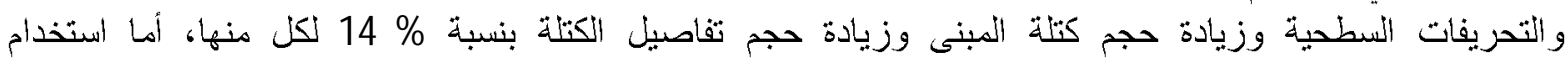

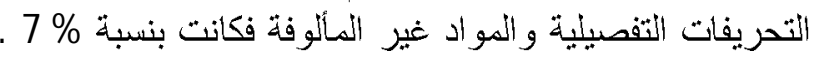
أما بالنسبة لكل نوع من أنو اع الخصائص فسيتم عرض نتائجها فيما يلي: 1.3.7 التحريفات الهندسية: جاء التركيز بشكل متساو على التحريفات الكتلوية والتحريفات السطحية والتحريفات

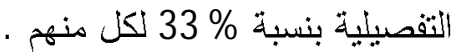
2.3.7 المبالغة الحجمية: وقد جاءت نسبة كل من زيادة حجم كتلة العبنى وزيادة حجم تفاصيلها بنسب متساوية هي \% 50 لكل منهما.

3.3.7 التلاعبات الغلافية: وقد ركزت زهاء حديد على استخدام مادة وملدس واحد لأجز اء من الغلاف بنسبة 75

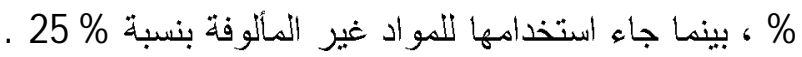

4.7 خصائص تجميع الكتل: وقد جاء جمع زهاء حديد للعناصر العمارية والهيكنية معا ضمن خاصية التمفصل

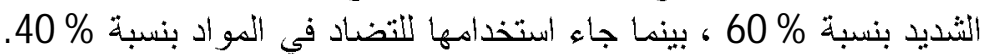

5.7 خرق المبادئ: تبين بعد القياس أن زهاء حديد تخرق مبادئ النهط الوظيفي، وكنلك مبادئ العلافة مع السياق

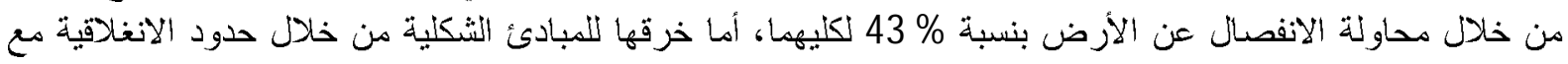
المحيط فكان بنسبة \% 14 .

6.7 إدراك الأثنكال النحتية:

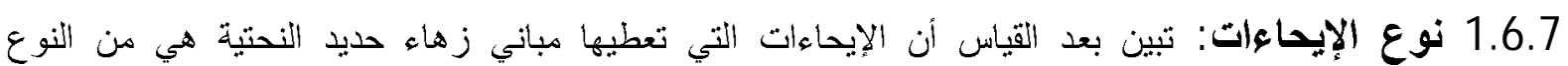
التجسيمي بنسبة \% 44 ، أما الإيحاء بالحركة والخفة فجاء بنسبة \% 28 ، بينسا جاءت الإيحاءات المعمارية و النفسية بنسب متساوية هي \% 14 كل كل منهما.

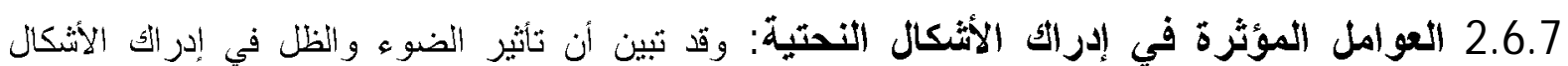

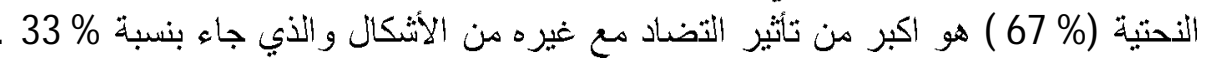

الجدول رقم ( 5 ) نتائج الدراسة العملية

\begin{tabular}{|c|c|c|c|c|c|c|c|}
\hline النسب المئوية & المجموع & $\begin{array}{r}\text { هبنى } \\
\text { BMW } \\
\text { المركزي }\end{array}$ & جعرض & مركزوع & & الفرعرية & المئيسرة|ت \\
\hline $33 \%$ & 1 & * & & & غاية بحد ذاته & & الدمعزر \\
\hline $67 \%$ & 2 & & $*$ & $*$ & تأثتير التنظوز الإنتُاني & & نحو النحتية \\
\hline $25 \%$ & 1 & & $*$ & & عضوي & \multirow{2}{*}{ الثصدرة } & \multirow{2}{*}{ الأشكالز } \\
\hline $50 \%$ & 2 & & $*$ & $*$ & مصنادر غبر متوقعة & & \\
\hline
\end{tabular}


ألدباغ: العمارة النحتية : توجه زها حديد

\begin{tabular}{|c|c|c|c|c|c|c|c|c|}
\hline & $25 \%$ & 1 & $*$ & & & مصداير وظيفية & & \\
\hline & $67 \%$ & 2 & $*$ & $*$ & & تحوير نظامي & \multirow{2}{*}{ النوظنبفر } & \\
\hline & $33 \%$ & 1 & & & $*$ & غير مبانشر تجريدي & & \\
\hline $14 \%$ & $33 \%$ & 2 & & * & * & تحريفات كتلوية & \multirow{3}{*}{ التهنديفات } & \multirow{7}{*}{ اللكتلز النصارجية } \\
\hline $14 \%$ & $33 \%$ & 2 & & * & * & تحريفات سطحية & & \\
\hline $14 \%$ & $33 \%$ & 2 & & * & $*$ & التحريفات التفصيلية & & \\
\hline $14 \%$ & $50 \%$ & 2 & & * & * & زيادة حجر كتلة المبنى & \multirow{2}{*}{ الحجمية } & \\
\hline $14 \%$ & $50 \%$ & 2 & $*$ & * & & زيادة حجم تفاصيل الكناة & & \\
\hline $7 \%$ & $25 \%$ & 1 & & * & & استخدام المو اد غبر المألوفة & \multirow{2}{*}{ الغلافية } & \\
\hline $23 \%$ & $75 \%$ & 3 & $*$ & * & * & الاجنخ أه من الغلادة ولفس واحد & & \\
\hline & $40 \%$ & 2 & $*$ & & $*$ & التضاد في المواد & التضاد & \multirow{2}{*}{ تجميع الكتل } \\
\hline & $60 \%$ & 3 & $*$ & * & * & عناصر معمارية و هيكلية معا & الثنديدل & \\
\hline & $43 \%$ & 3 & $*$ & * & $*$ & خلتقزئي المطلب الوظيفي & الألونيفي & \multirow[t]{3}{*}{ خرق مبادئ } \\
\hline & $43 \%$ & 3 & $*$ & * & $*$ & الانفصنال أو محاولة الانفصدال & العياق القة مع & \\
\hline & $14 \%$ & 1 & & * & & حدو الآنغلآقية & 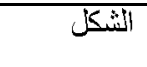 & \\
\hline & $28 \%$ & 2 & $*$ & & $*$ & الإيحاء بالكركة و الخفة & \multirow{4}{*}{ الإيحاءات } & \multirow{6}{*}{ الإلتزيكال } \\
\hline & $14 \%$ & 1 & & & $*$ & الإيحاءات النفسية & & \\
\hline & $44 \%$ & 3 & $*$ & * & * & الإيحاءات التجنيمية & & \\
\hline & $14 \%$ & 1 & $*$ & & & الإيحاءات المعمارية & & \\
\hline & $67 \%$ & 2 & & $*$ & $*$ & الضوء و الظل & \multirow{2}{*}{ الإلدؤثرة في } & \\
\hline & $33 \%$ & 1 & $*$ & & & وغيرهاد بين الثنكل ألنحني & & \\
\hline
\end{tabular}

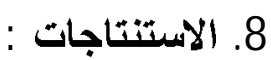

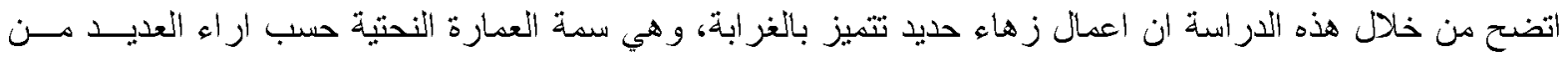

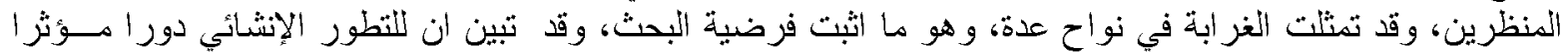

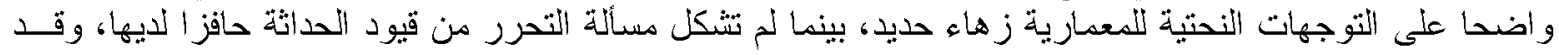

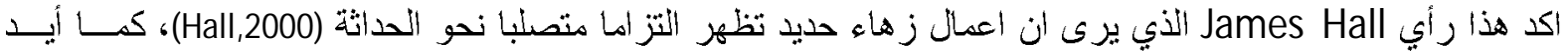
أيضا رأي Jencks الذي أكد بشكل عام ان الثكل النحتي جاء بتأثير التطور التقني (Jencks,1988,p22).

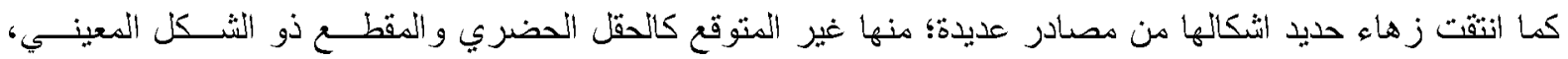

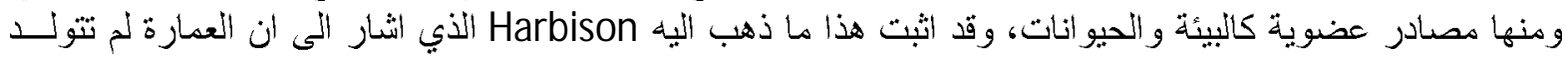
من العمارة ولكن هن تصور ونة كات شكية اكثر عمومية (Harbison,1997,p6).

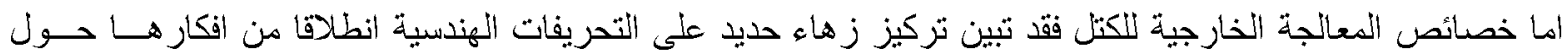

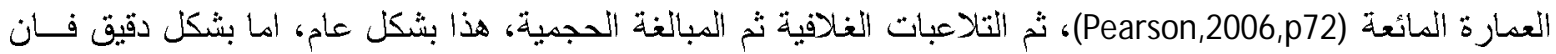

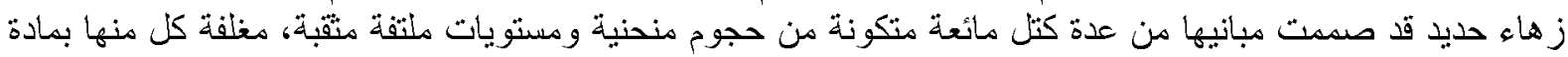



Al-Rafidain Engineering
Vol.19
No.1
February 2011

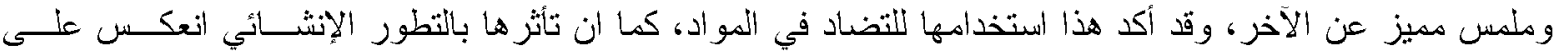

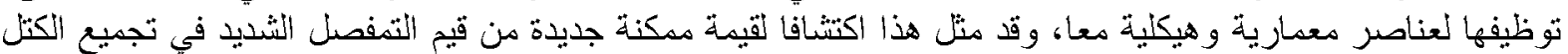

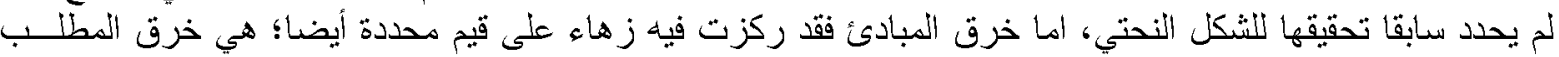

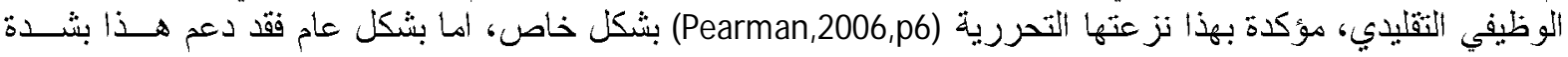

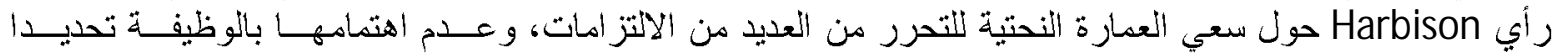

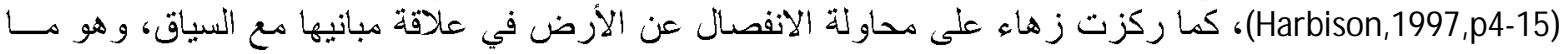

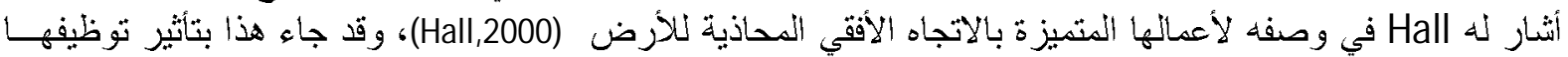
للإمكانيات الإنثائية المتطورة أيضا.

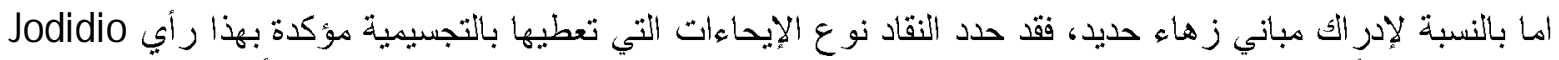

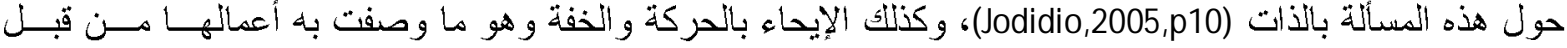
العديد من النقاد (Hall,2000)و (Gannon,2006)و (Pearman,2006).

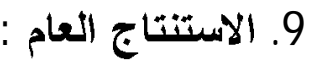

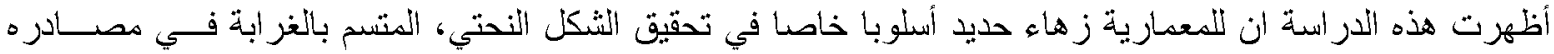

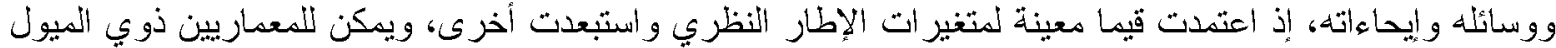

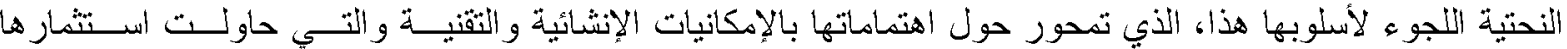

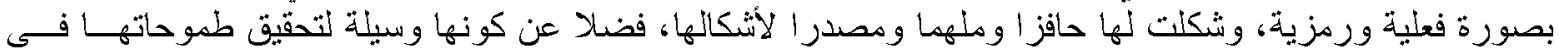

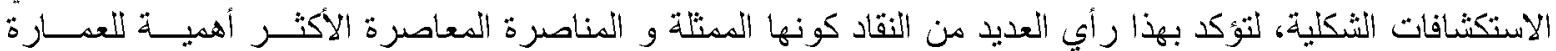
النحنية، على حد تعبير James Hall

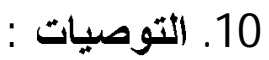

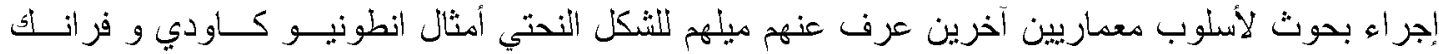
جيري و سانتياغو كالاتر افا. - البحث في تطور أسلوب زهاء حديد النحتي من بداية أعمانها ونحد الآن . - - تطبيق أسلوب زهاء حديد من قبل المعماريين و الطلبة ذوب الميول لتحقيق التشكل النحتي .

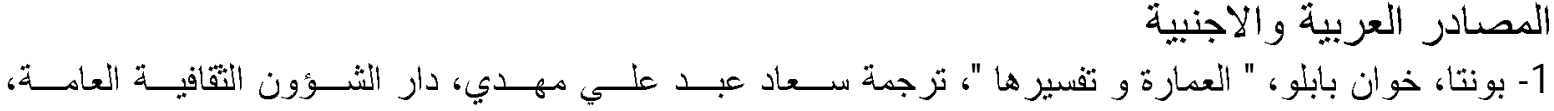
آفاق عربية، 1996

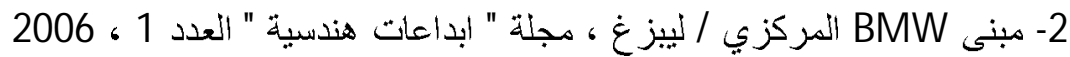

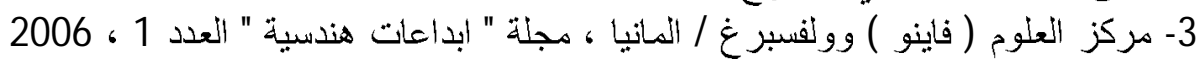
4- السلطاني، خالد " نخلة غاودي " صفدة عمارة وتثكيل، جريدة المدى/www.almadapaper.com

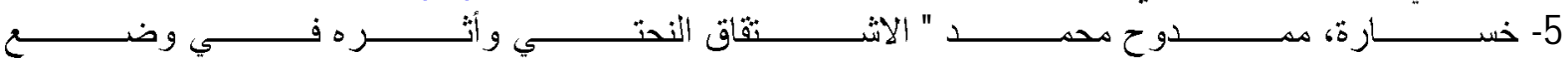

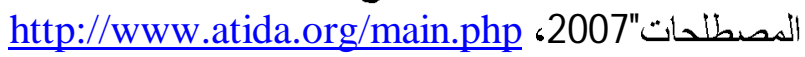

6- Anuual Report , 2004 , www.bmwgroup.com/e/0 0 www.../gb2004 gesamt.pdf

7- " About Azurean Sculpture +Architecture" , 2002, operations@ azurean.ca

8- Barreneche, Raul A. " Architectural Record " August, 2005

9- Brubaker Steve "Sculptural Forms add Creativity, Visual Impact- Article XII " 10- D,Souza, Aruna $\&$ M cDonough, Tom " Sculpture in the space of architecture " , 2000 11- Gannon, Todd " Zaha Hadid / BMW central building : Source book in architecture 7 " Princeton Architectural Press, 2006 
12- Hall, James " Zaha Hadid -Brief Article " Arts Publications, Institute of contemporary art forum, International Magazine, Inc. Nov. 2000

13- Harbison, Robert "Sculpture " from "Thirteen Ways : Theoretical Investigations in Architecture "Massachusetts Institute of Technology, 1997

14- Jencks, Charles " Architecture Today " 1988

15- Jodidio, Philip "Architecture : Art "Prestel Verlag, M unich, 2005, www.Amazon.com

16- Krawczyk, Robert J. " Sculptural Interpretation of a Mathmatical Form " College of Architecture, Illinios Institute of Tchnology, 2002, Towson University

17- Pearman, Hugh " Iraqitect: Zaha Hadid commands the Goggenheim, but remember her roots " Gabion, Retained Writing on Arhitecture," Sunday Times Magazine " 4, June, 2006

18- Pearson, Clifford A. " Architectural Record " February, 2006

19- Phaeno Science Center, Wolfsburg, Germany, www.ces.de

20- Science Center Wolfsburg, www.press@zaha-hadid.com

21- Sungur, Elif, "Dialogues between Architecture and Sculpture ", Dexigner, 2006, www.europaconcorsi.com/

22- Zaha completes in Wolfsburg, 2005, www. World architecture news.com

23- Zaha Hadid Architects, Phaeno Science Center, Wolfsburg, Germany, www.Arcspace.com

24- Zaha Hadid Architects, Zaragoza Bridge Pavilion, Zaragoza, Spain, www .Arcspace.com

25- Zaragoza Bridge Pavilion in Spain as symbol of Zaragoza Expo by Zaha Hadid, www.dezeen.com

26- Zaragoza Bridge Pavilion, Zaragoza, Spain, 2008, www. World architecture news.com

27-Zaragoza 2008 Expo Bridge +Pavilion,www.info@e-architect.co.uk 